UNIVERSIDADE DE SÃO PAULO

PROGRAMA DE PÓS-GRADUAÇÃO EM CIÊNCIA AMBIENTAL

PILAR CAROLINA VILLAR

A BUSCA PELA GOVERNANÇA DOS AQUÍFEROS

TRANSFRONTEIRIÇOS E O CASO DO AQUÍFERO GUARANI

SÃO PAULO

2012 
PILAR CAROLINA VILLAR

\section{A BUSCA PELA GOVERNANÇA DOS AQUÍFEROS TRANSFRONTEIRIÇOS E O CASO DO AQUÍFERO GUARANI}

Tese apresentada ao Programa de Pós-Graduação em Ciência Ambiental (PROCAM) da Universidade de São Paulo para a obtenção do título de Doutor em Ciência Ambiental

Orientador: Wagner Costa Ribeiro

Versão Revisada

(versão revisada disponível na Biblioteca do Instituto de Energia e Eletrotécnica e na Biblioteca Digital de Teses e Dissertações da USP

SÃO PAULO

2012 
AUTORIzO A REPRODUÇÃo E DIVULGaÇÃO TOTAL OU PARCIAL DESTE TRABALHO, POR QUALQUER MEIO CONVENCIONAL OU ELETRÔNICO, PARA FINS DE ESTUDO E PESQUISA, DESDE QUE CITADA A FONTE.

FICHA CATALOGRÁFiCA

Villar, Pilar Carolina .

A busca pela governança dos aquíferos transfronteiriços e o caso do aquífero guarani. / Pilar Carolina Villar; orientador Wagner Costa Ribeiro. - São Paulo, 2012.

$259 \mathrm{f}$. : il.; $30 \mathrm{~cm}$.

Tese (Doutorado) - Programa de Pós-Graduação em Ciência Ambiental, Universidade de São Paulo , 2012.

1. Aquífero Guarani 2.Aquíferos transfronteiriços 3. Crise hídrica 4. Cooperação internacional 5. Direito internacional I. Título. 


\section{FOLHA DE APROVAÇÃO}

Pilar Carolina Villar

A Busca pela Governança dos Aquífero Transfronteiriços e o Caso do Aquífero Guarani.

Tese de Doutorado apresentada ao Programa de Ciência Ambiental da Universidade de São Paulo, para obtenção do título de Mestre em Ciência Ambiental.

Aprovado em:

\section{Banca Examinadora}

Prof. Dr. Wagner Costa Ribeiro (orientador)

Programa de Ciência Ambiental - PROCAM/USP

Faculdade de Filosofia, Letras e Ciências Humanas - USP

Profa. Dra Ana Flávia Barros-Platiau

Instituto de Relações Internacionais - UNB

Profa. Dra. Cristiane Derani

Centro de Ciências Jurídicas - UFSC

Profa. Dra. Elizabeth de Almeida Meirelles

Faculdade de Direito - USP

Prof. Dr. Pedro Jacobi

Programa de Ciência Ambiental - PROCAM/USP

Faculdade de Educação - USP

Parecer da Banca Examinadora 
Dedico esta tese a minha mãe, Margarita Antônia Villar Luis, meu eterno exemplo na academia e na vida. 


\title{
AGRADECIMENTOS
}

\author{
"Caminante, no hay camino \\ se hace camino al andar." \\ Antonio Machado
}

A elaboração de uma tese é uma aventura. O texto que apresento é o resultado de uma longa viagem rumo ao conhecimento, que se iniciou em 2009, marcada por momentos de alegria, abatimento, iluminação, glamour, deslumbramento, apatia ou simplesmente contemplação. $\mathrm{O}$ caminho da tese foi feito "golpe a golpe, verso a verso" como diria o poeta Antonio Machado. Porém, esse resultado não seria o mesmo, se em minha jornada não tivesse a companhia, a solidariedade, o apoio e a ajuda de uma série de pessoas especiais, as quais gostaria de prestar esta singela homenagem:

Ao meu orientador, amigo e padrinho de casamento, Wagner Costa Ribeiro, que acreditou e endossou todos os meus projetos desde o mestrado, ainda que alguns tenham demandado um longo exercício de argumentação.

Ao meu marido, amor, amigo e companheiro, Etienne Lainé, que me inspira, acalma, incentiva e me faz acreditar que tudo é possível. Todas as aventuras se tornam possíveis e melhores ao seu lado.

À minha mãe, amiga, conselheira e exemplo, Margarita Antônia Villar Luis, pelo seu apoio, experiência e visão. Obrigada por estar sempre presente e pronta para me ajudar, inclusive no marco teórico desta tese.

Ao PROCAM e a CAPES por terem acreditado em meu potencial e financiado esta tese.

À professora Vitória Régia Fernandes Gehlen, que me acolheu no seu grupo de pesquisa de coração aberto, me apresentou a teoria crítica e me permitiu abraçar projetos extremamente desafiantes.

À professora Rosa Ester Rossini, por sua contribuição inestimável ao meu marco teórico, e por me apresentar a obra de Milton Santos.

Ao Professor Pedro Jacobi, que acompanhou toda a minha trajetória no PROCAM e sempre me forneceu bons conselhos e apoio.

Aos professores das minhas disciplinas de doutorado que contribuíram para minha formação acadêmica: Ana Paula Fracalanza, Elizabeth de Almeida Meirelles, Juan Luis Suárez de Vivero, Paulo Borba Casella, Pedro Bohomoletz de Abreu Dallari e Pedro Roberto Jacobi.

Aos membros da banca de qualificação, Professor Pedro Jacobi e a Professora Cristiane Derani que ao partilharem as suas opiniões me obrigaram a enxergar a tese com uma nova perspectiva. 
As amigas de doutorado Carolina Gamba, Camila Lomba Pacheco, Fernanda Mello Sant'Anna e Helena Margarido Moreira que me ajudaram com referências, conceitos, discussões de teorias ou simplesmente ouviram minhas inquietações.

As companheiras do direito Juliana Cassano Cibim e Carolina de Abreu B. Claro sempre prontas a discutir o direito internacional ou a governança.

Aos amigos do Grupo de Estudos e Pesquisas em Gênero, Raça, Meio Ambiente e Planejamento em Políticas Públicas da Universidade Federal de Pernambuco (GRAPP/UFPE), especialmente a Gilvana Pessoa Oliveira, Maria Magaly Colares de Moura Andrade, Rosiglay Cavalcante de Vasconcellos e Tarcisio Augusto Alves que me mostraram novas abordagens, novos temas de pesquisa e me acompanharam nos desafios pernambucanos paralelos à tese.

Aos amigos do Grupo de Pesquisa Geografia Política e Recurso Naturais da Universidade de São Paulo.

Ao professor Ernani Francisco da Rosa Filho por partilhar sua experiência, conhecimento e história no processo de cooperação do Aquífero Guarani.

Ao professor Gabriel Eckstein, por suas valiosas contribuições na discussão do direito internacional dos aquíferos transfronteiriços.

Ao professor Enrique Leff, por me mostrar que a curiosidade é fundamental em todo o pesquisador e me ajudar a compreender suas ideias e aplicá-las no meu caso prático.

À professora Lilian Castillo-Laborde por esclarecer vários conceitos e interpretações sobre o direito internacional das águas doces.

Ao Luciano Souza, do PROCAM/IEE/USP, pela ajuda, pela gentileza e pela amizade de tantos anos.

À Fundação Carolina e aos professores do Curso de Instrumentos e Políticas Gestão Ambiental na Europa, Instituto Universitário de Estudos Europeus, Universidade CEU San Pablo, que ampliaram a minha visão sobre gestão ambiental e me permitiram conhecer mais da Espanha, da Europa e da América Latina.

Aos amigos latino-americanos que conheci graças à Fundação Carolina: Amparito, Ana, Andrea, Carolina, Diana, Elsy, Jenny, Lisandro, Ludgar, Moara, Roseli, Santiago, Simone, que me apresentaram novas realidades e oportunidades.

Aos colegas do curso de Gestão Ambiental da UFSCAR, que me receberam com tanta cortesia. A disciplina de economia do meio ambiente deixou suas marcas nesta tese.

À ISARM/UNESCO cujo financiamento me permitiu vivenciar a grandiosidade e densidade das conferências patrocinadas pela UNESCO, ver a apresentação das minhas referências bibliográficas, participar de um curso sobre águas subterrâneas ao lado delas e ainda ter a honra de expor um trabalho na sede da UNESCO em Paris. 
À CAP-NET/África e ao PNUD pelo financiamento e oportunidade de participar do curso Trainers Course on Groundwater Management in IWRM, que me permitiu entender os fundamentos básicos da gestão integrada dos recursos hídricos subterrâneos e conhecer pessoas maravilhosas como Monica Delia e Marina Christofidis.

À WWF e à University of Dundee, cujo financiamento me permitiu participar da $U N$ Watercourses Convention, e discutir sobre o direito internacional das águas doces com as minhas principais referências: Attila Tanzi, Owen McIntyre, Stefano Burchi e Stephen McCaffrey. Essa conferência foi fundamental para aprimorar o capítulo do direito internacional das águas doces e consolidar minha visão de soberania.

À European Association of Environmental and Resource Economists (EAERE) e à International University of Venice por incorporar uma advogada no curso European Summer School "Management of International Water" e por me fulminarem com questionamentos sobre o caso do Aquífero Guarani. A objetividade econômica os comentários sobre minha apresentação me fizeram repensar toda a abordagem do processo de cooperação do Guarani. Agradecimentos especiais aos professores: Ariel Dinar, Ines Dombrowsky e Shlomi Dinar por suas preciosas orientações e pela festa surpresa de aniversário.

Aos amigos que conheci no curso da EAERE, agradecimentos especiais a Emeline Hassenforder que me forneceu dados preciosos sobre o Projeto Sistema Aquífero Guarani e a Laura Movilla Pateiro, que se mostrou uma ótima parceira para discussões e trocas de bibliografia.

A todos aqueles que o diante do cansaço desta reta final, esqueci-me de nomear. 


\section{RESUMO}

VILLAR, P. C. A Busca por uma Governança dos Aquíferos Transfronteiriços e o caso do Aquífero Guarani. 2012. 259f. Tese (Doutorado) - Programa de Pós Graduação em Ciência Ambiental (PROCAM) Universidade de São Paulo, São Paulo, 2012.

Os recursos hídricos subterrâneos abastecem milhões de pessoas no mundo e constituem a principal reserva hídrica disponível para os seres humanos, contudo sua gestão é precária. A eminência de uma crise hídrica redirecionou os holofotes para os aquíferos transfronteiriços, o que demonstrou sua vulnerabilidade aos riscos e a necessidade de inseri-los nas políticas hídricas nacionais e internacionais. Gradualmente, o sistema internacional busca formas de incluir esses recursos e promover a sua governança e gestão. Esse foi o caso do Aquífero Guarani, alvo de diversos projetos de cooperação que convergiram no único acordo para a gestão conjunta de um aquífero transfronteiriço na América. $O$ objetivo deste trabalho é analisar como o direito internacional e a ordem ambiental internacional trataram a temática das águas subterrâneas e dos aquíferos transfronteiriços e quais são as suas estratégias para combater os riscos que ameaçam esses recursos, com foco no caso do aquífero Guarani. A metodologia utilizada foi a análise qualitativa de documentos internacionais e da bibliografia, e a realização de entrevistas com especialistas sobre o tema. O direito internacional das águas doces, voltado quase que exclusivamente para os cursos de água internacionais, se desdobra para incluir os aquíferos, o que se reflete em várias tentativas da comunidade epistêmica jurídica e na edição da Resolução da Assembleia Geral das Nações Unidas n ${ }^{\circ}$ 63/124 - o direito internacional dos aquíferos transfronteiriços. Paralelamente, o sistema internacional, representado por um grupo específico de organizações internacionais busca traçar diretrizes objetivas e universais para esses recursos, tendo elegido a gestão integrada e a boa governança das águas como a melhor forma de protegê-los. Esses conceitos convidam a um aprofundamento da cooperação e a constituição de marcos jurídicos conjuntos, que podem contribuir para a elaboração de algum tipo de política de uso e proteção. Porém não questionam o cerne do problema que é a racionalidade econômica dominante. A cooperação internacional estabelecida entre Argentina, Brasil, Paraguai e Uruguai para o Aquífero Guarani e a assinatura de seu respectivo acordo são fruto desse contexto internacional que tem promovido à temática das águas subterrâneas. $\mathrm{O}$ modelo de cooperação adotado no Guarani vai replicar a ordem ambiental e o direito internacional das águas doces e expor seus avanços, limitações e contradições.

Palavras chave: Aquífero Guarani. Aquíferos transfronteiriços. Cooperação internacional. Crise Hídrica. Direito internacional das águas doces. 


\begin{abstract}
VILLAR, P. C. Seeking Transboundary Aquifer Governance and the Guarani Aquifer Case. 2012. 259f. Thesis (Ph D Degree) - Postgraduate Program in Environmental Sciences, University of São Paulo, São Paulo, 2012.
\end{abstract}

Groundwater resources supply millions of people worldwide and constitute the main water reserve available for mankind, but its management is precarious. The eminence of a water crisis redirected the spotlights to transboundary aquifers, which made evident their vulnerability to the risks and the need to insert them in the national and international water policies. Gradually, the international system seeks ways of including these resources and promoting their governance and management. This was the case of the Guarani Aquifer, the target of several cooperation projects that led to the only agreement for the joint management of a transboundary aquifer in America. The aim of this study is to analyze how international law and the environmental order treated the groundwaters and transboundary aquifers and what are their strategies to avoid the risks that threaten these resources, focused on the case of the Guarani Aquifer. The methodology used is the qualitative analysis of international documents and the bibliography on the theme. International water law, directed almost exclusively to surface water resources, makes efforts to include the aquifers, which is reflected in several attempts from the legal epistemic community and the edition of UN Resolution 63/124 - the international law of transboundary aquifers. Parallel to this, the international system, represented by a specific group of international organizations, aims at drafting objective and universal guidelines for these resources, having elected the integrated water resources management and good water governance as the best way to protect them. These concepts are an invitation to dive deeper into the cooperation and constitution of joint legal landmarks, which can contribute, at least, to formatting some type of use and protection policy. Nevertheless, they do not question the core problem, which is the dominating economic rationale. The international cooperation established between Argentina, Brazil, Paraguay and Uruguay for the Guarani Aquifer and the signature of the respective agreement are the result of this international context that has promoted the groundwater theme. The cooperation model adopted for the Guarani will replicate the international environmental order and international water law and expose their advances, limitations and contradictions.

Key words: Guarani aquifer. Transboundary aquifers. International cooperation. Water crises. International water law. 


\section{LISTA DE FIGURAS}

Figura 1: A sequência dos problemas de qualidade das águas que aparecem nos países industrializados.

Figura 2: Diferenças entre águas subterrâneas/aquíferos e águas superficiais /reservatórios.

Figura 3: Sistemas Aquíferos Transfronteiriços no Mundo........................................ 55

Figura 4: Indicador de Risco Hídrico nas principais Bacias Hidrográficas.............. 56

Figura 5: $\quad$ Sistemas Aquíferos Transfronteiriços da América do Sul.......................... 59

Figura 6: Fluxo Hídrico de um Sistema de Águas Subterrâneas Transfronteiriço..... 64

Figura 7: Estados Ribeirinhos e os Aquíferos Transfronteiriços - Tipo 1 e Tipo 2... 66

Figura 8: $\quad$ Estados Ribeirinhos e os Aquíferos Transfronteiriços - Tipo 3 e Tipo 4... 67

Figura 9: $\quad$ Estados Ribeirinhos e os Aquíferos Transfronteiriços - Tipo 5 e Tipo 6... 67

Figura 10: O Processo de Codificação das Águas Subterrâneas e Aquíferos Transfronteiriços..................................................................................... 105

Figura 11: A Ordem Ambiental Internacional e as Águas Transfronteiriças............... 140

Figura 12: Organizações Internacionais e suas Responsabilidades Hídricas no Plano de Ação para o Meio Ambiente, Estocolmo, 1972 ..................................... 146

Figura 13: Esquema da Evolução da Cooperação no Sistema Aquífero Guarani....... 189

Figura 14: O Sistema Aquífero Guarani e suas Zonas de Gestão................................ 191

Figura 15 Sistema Aquífero Guarani e áreas com Potencial de Risco de conflito transfronteiriço.

Figura 16: Síntese das Componentes do Projeto Sistema Aquífero Guarani: Ações, Custos e Organizações Participantes. 


\section{LISTA DE SIGLAS}

$\begin{array}{ll}\text { AIEA } & \text { Agência Internacional de Energia Atômica. } \\ \text { AIH } & \text { Associação Internacional de Hidrogeologia. } \\ \text { ADI } & \text { Associação de Direito Internacional. } \\ \text { BGR } & \text { Bundesanstalt fuer Geowissenschaften und Rohstoffe. } \\ \text { BM WPP } & \text { Banco Mundial Water Partnership Program } \\ \text { BNWPP } & \text { Bank Netherlands Water Partnership Program. } \\ \text { CDI } & \text { Comissão de Direito Internacional da Organização das Nações Unidas. } \\ \text { CIJ } & \text { Corte Internacional de Justiça. } \\ \text { CPIJ } & \text { Corte Permanente Internacional de Justiça. } \\ \text { ECOSOC } & \text { United Nations Economic and Social Council. } \\ \text { FAO } & \text { Organização para Agricultura e Alimentação. } \\ \text { FAMA } & \text { Fórum Alternativo Mundial da Água. } \\ \text { FMA } & \text { Fórum Mundial da Água. } \\ \text { GEF } & \text { Fundo Mundial para o Meio Ambiente. } \\ \text { GIRH } & \text { Gestão Integrada dos Recursos Hídricos. } \\ \text { GWP } & \text { Global Water Partnership. } \\ \text { IDI } & \text { Instituto de Direito Internacional. } \\ \text { PHI } & \text { Programa Hidrológico Internacional. } \\ \text { ISARM } & \text { Internationally Shared Aquifer Resource Management. } \\ \text { OEA } & \text { Organização dos Estados Americanos. } \\ \text { OIT } & \text { Organização Internacional do Trabalho. } \\ \text { OMM } & \text { Organizção Mundial de Meteorologia. } \\ \text { OMS } & \text { Organização Mundial da Saúde. } \\ \text { ONU } & \text { Organização das Nações Unidas. } \\ \text { OSS } & \text { Observatoire du Sahara et du Sahel. } \\ \text { PNUD } & \text { Programa das Nações Unidas para o Desenvolvimento. } \\ \text { PNUMA } & \text { Programa das Nações Unidas para o Meio Ambiente. } \\ \text { PSAG } & \text { Projeto Sistema Aquífero Guarani. } \\ \text { SAG } & \text { Sistema Aquífero Guarani. } \\ \text { SISAG } & \text { Sistema de Informação do Sistema Aquífero Guarani. } \\ \text { TARM } & \text { Transboundary Aquifer Resource Management. } \\ \text { TFDD } & \text { Transboundary Freshwater Dispute Database. } \\ \text { UNDESA } & \text { United Nations Department of Economic and Social Affairs. } \\ \text { UNECE } & \text { United Nations Economic Commission for Europe. } \\ \text { UNESCO } & \text { United Nations Educational, Scientific and Cultural Organization. } \\ \text { UNICEF } & \text { United Nations Children's Fund. } \\ & \end{array}$




\section{SUMÁRIO}

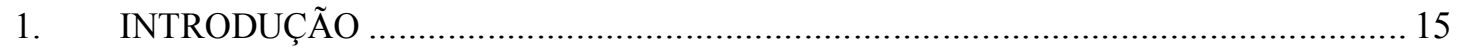

2. A CRISE HÍDRICA E OS AQUÍFEROS TRANSFRONTEIRIÇOS.............................. 21

2.1. A problemática ambiental e a Sociedade de Risco Mundial................................................. 22

2.1.1. Desdobramentos da crise ambiental: a crise hídrica....................................................30

2.2. A crise hídrica na perspectiva das águas subterrâneas e aquíferos ...................................... 37

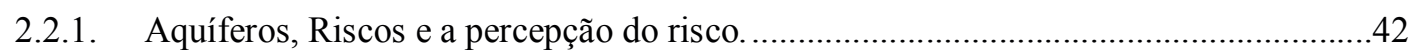

2.3. Os Sistemas Aquíferos Transfronteiriços no Mundo ............................................................. 53

2.3.1. Os aquíferos transfronteiriços na América do Sul......................................................58

2.4. A problemática dos aquíferos transfronteiriços: recurso natural e crise compartilhados. .. 62

2.5. Conflito ou cooperação internacional na gestão da crise dos aquíferos.............................. 68

2.6. A busca por uma soberania compartilhada dos aquíferos transfronteiriços......................... 72

3. O DIREITO INTERNACIONAL DAS ÁGUAS DOCES E OS AQUÍFEROS

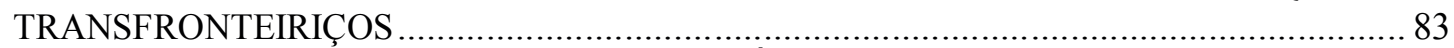

3.1. A Construção do Direito Internacional das Águas Doces Transfronteiriças ....................... 85

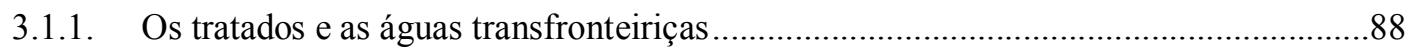

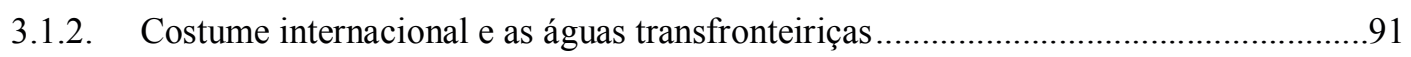

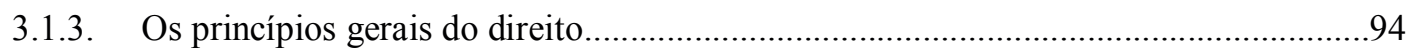

3.1.4. A doutrina e a jurisprudência na construção do direito internacional das águas

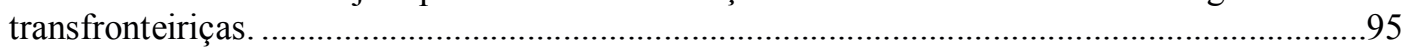

3.2. O Processo de codificação do direito internacional das águas doces e a inclusão dos

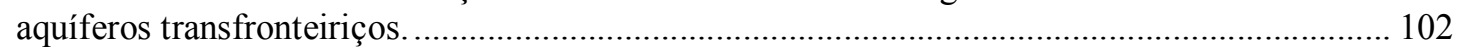

3.3. Declaração de Madri (1911) e a Resolução de Salzburg (1961)......................................... 104

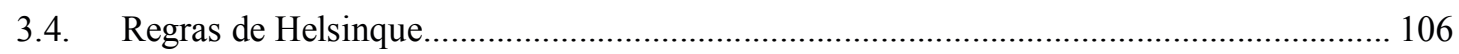

3.5. As regras de Seul para as águas subterrâneas internacionais.......................................... 108

3.6. Anteprojeto de Tratado Bellagio para as águas subterrâneas transfronteiriças.................. 109

3.7. Convenção das Nações Unidas sobre o Direito relativo aos usos dos cursos de água internacionais para fins distintos da navegação e as águas subterrâneas........................................ 111

3.7.1. Os princípios norteados de direito internacional das águas doces...............................115

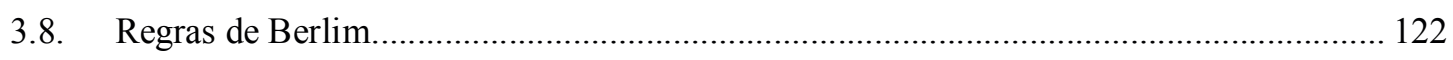

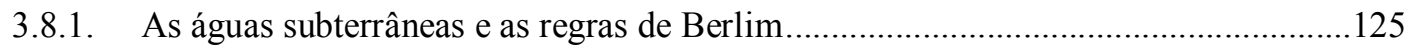

3.9. Resolução da Assembleia Geral das Nações Unidas 63/124 - O Direito dos Aquíferos

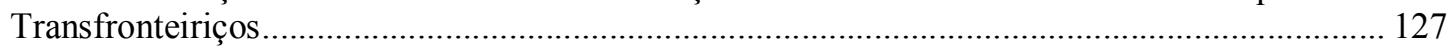

4. A ORDEM AMBIENTAL INTERNACIONAL E OS AQUÍFEROS TRANSFRONTEIRIÇOS ……............................................................................ 136

4.1. Os antecedentes das conferências de Estocolmo e Mar de Plata ....................................... 140

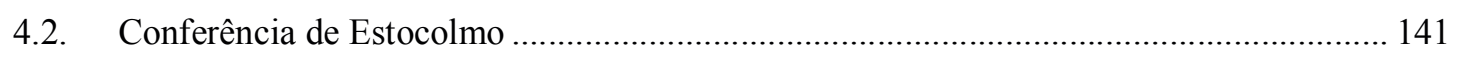

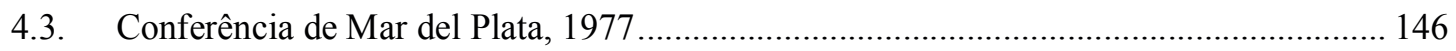


4.4. De Estocolomo à Rio 92: o mundo se transforma.

4.4.1. Conferência de Dublin, 1992

4.5. Conferência do Rio de Janeiro, Rio-92

4.6. Uma nova ordem mundial da água

4.6.1. Conferência de Bonn, 2001

4.6.2. Cúpula Mundial sobre Desenvolvimento Sustentável

4.7. Conferência das Nações Unidas sobre Desenvolvimento Sustentável, Rio +20

4.8. As organizações internacionais e os aquíferos transfronteiriços

4.9. Governança das águas e a gestão integrada dos recursos hídricos transfronteiriços a saída internacional para a crise hídrica?

5. O AQUÍFERO GUARANI: A BUSCA POR UM NOVO PARADIGMA DE COOPERAÇÃO 185

5.1. O Sistema Aquífero Guarani: recurso compartilhado, mas com ressalvas. ..................... 188

5.2. A comunidade epistêmica e a descoberta do Aquífero Guarani ...................................... 194

5.3. Projeto Sistema Aquífero Guarani: a cooperação internacional se expande.................... 197

5.4. O Aquífero Guarani ganha espaço no Mercosul ......................................................... 204

5.5. O acordo sobre o Aquífero Guarani: novo paradigma ou irresponsabilidade organizada 210

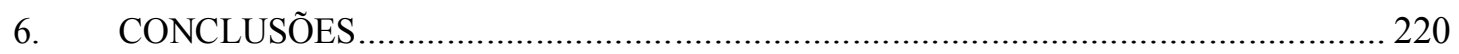

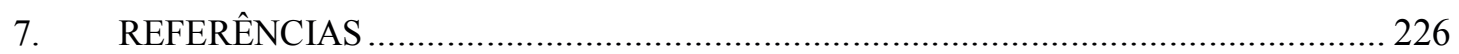




\section{INTRODUÇ̃̃O}

Milhões de pessoas ao redor do mundo utilizam as águas subterrâneas, seja em pequenas comunidades ou grandes centros urbanos, em diversos países, ricos ou pobres. Essas águas representam o principal recurso hídrico disponível para a humanidade, apesar disso, ainda são tratadas como um recurso de categoria secundária em comparação às águas superficiais. Afinal, elas não possuem o prestígio ou a poesia dos rios que cortam territórios, serpenteando pelos vales e refletindo a paisagem em suas águas cheias de vida; nem chocam os sentidos pela imagem ou cheiro dos corpos superficiais degradados.

As águas subterrâneas são acanhadas, não se revelam aos olhos, só se pode espiá-las, como quando se olha pelo buraco da fechadura, que no caso, seria o poço, tentando desvendar os mistérios ocultos do outro lado. Porém, essas águas também se aventuram pelo território, inclusive se imiscuem com ele, atravessam fronteiras e têm múltiplos destinos, definidos pela configuração da formação geológica que as abriga e pelo uso humano. E, em muitos casos, essas águas, de forma despercebida, resurgem à superfície abastecendo ostensivos sistemas hídricos superficiais, de bacias hidrográficas internacionais.

Quando se fala em águas subterrâneas pretende-se abarcar toda a água contida nos espaços porosos das rochas e do solo. Os aquíferos correspondem às formações geológicas com quantidade de água significativa. Apesar das semelhanças entre esses termos, há distinções importantes: os aquíferos contêm águas subterrâneas, mas nem toda água subterrânea corresponde a um aquífero; além disso, o termo água subterrânea não compreende a formação geológica que a abarca, já o conceito de aquífero compreende essa formação e exige que ela contenha volumes consideráveis de água subterrânea.

A natureza velada dessas águas acobertou sua real importância, excluindo-as das políticas locais, nacionais ou internacionais. Porém, pelo menos no âmbito internacional, essa "Cinderela já fez sua entrada no baile", e os convidados pouco a pouco começam a notá-la. A crise hídrica causada por uma racionalidade econômica pautada no domínio da natureza continua a se agravar, novos riscos se somam aos problemas antigos, ainda pendentes de solução, enquanto a demanda por água continua a crescer progressivamente. Nesse cenário, os atores internacionais são obrigados a olhar para baixo e a buscar formas de incluir as águas subterrâneas e os aquíferos na pauta da agenda internacional. 
A partir desse momento, os aquíferos transfronteiriços ganham destaque diante da dificuldade em criar arranjos adequados para a gestão de formações geológicas com água, que se encontram sob o jugo de soberanias distintas. A água pode se tornar alvo de conflitos e/ou cooperação. Essa cooperação pode-se de dar de diversas formas, por meio de acordos bilaterais, multilaterais, iniciativas da diplomacia multilateral, intercâmbio técnico, entre outros. No final da década de noventa, a literatura sobre águas incorporou o termo governança como uma forma de abranger todas essas ações realizadas pelos países para promover a gestão das águas. O conceito de governança é amplo e não possui uma definição precisa, a mais conhecida é a do Global Water Partnership (2002, p. 1) que a definiu como o conjunto de "sistemas políticos, sociais, econômicos e administrativos disponíveis para aproveitar e gerenciar os recursos hídricos, e distribuir os serviços hídricos nos distintos níveis da sociedade".

A amplitude do conceito permite diversas formas de abordagem, por isso este trabalho se restringiu a análise do direito internacional das águas doces, da ordem ambiental internacional e do estudo do caso prático do aquífero Guarani. Dessa forma, a busca pela governança dos aquíferos transfronteiriços mencionada no título visa justamente verificar como o direito e a ordem ambiental internacional têm lidado com o tema das águas subterrâneas transfronteiriças e como suas construções foram incorporadas ao caso do Aquífero Guarani.

O direito internacional das águas doces, voltado quase que exclusivamente para as águas superficiais, se desdobra para incluir os aquíferos, corpos complexos e heterogêneos. Para isso faz alianças com outras ciências e outros direitos, e se vê desafiado a reinterpretar seus postulados. Paralelamente, a ordem ambiental internacional, responsável por configurar os ideais de gestão integrada dos recursos hídricos e de governança das águas, assume o papel de buscar diretrizes para os aquíferos transfronteiriços e incluí-los dentro das prioridades de gestão.

Dito isso, a hipótese deste trabalho é de que o processo de cooperação para o aquífero Guarani partilhado entre Argentina, Brasil, Paraguai e Uruguai foi influenciado por esse cenário internacional que incentiva a temática das águas subterrâneas. A elaboração de projetos internacionais e a assinatura de um acordo para esse aquífero reflete um fenômeno maior, que é o papel da ordem ambiental internacional e do direito internacional na priorização de determinados assuntos que passam a ser incorporados pelos Estados. Partindo dessa premissa, este trabalho assumiu como objetivo analisar como o direito e a ordem 
ambiental internacional incluíram a temática das águas subterrâneas e dos aquíferos transfronteiriços e como isso repercutiu no caso do aquífero Guarani.

Seu foco reside principalmente em concentrar a análise do direito e da ordem ambiental internacional na perspectiva das águas subterrâneas e não nas superficiais, ainda que estas sejam abordadas. Além disso, verificar com base no caso do Aquífero Guarani, como essa articulação internacional vai influenciar um processo de cooperação regional entre quatro países.

Como forma de atingir os objetivos propostos à pesquisa foi dividida em quatro partes: 1) examinar a crise hídrica à luz da teoria social de risco, priorizando as águas subterrâneas e os aquíferos transfronteiriços; 2) avaliar como o direito internacional das águas doces incorporou a temática das águas subterrâneas e dos aquíferos transfronteiriços; 3) verificar como a ordem ambiental internacional abordou as águas subterrâneas e os aquíferos transfronteiriços e como ela contribuiu para promover a sua gestão; e 4) analisar como se deu o processo de cooperação internacional no caso do Aquífero Guarani e os seus principais desdobramentos.

Este trabalho se pauta por uma lógica interdisciplinar, baseada na literatura do direito internacional, da economia, da geografia, da geologia, das relações internacionais, da sociologia e das teorias socioambientais. A atenção internacional dedicada aos aquíferos é fruto de uma crise ambiental, cuja compreensão demanda a integração de diversos campos do conhecimento e de saberes não científicos (LEFF, 2001). Dessa forma, apesar da formação jurídica da autora, buscou-se aprender e incorporar a visão de outras ciências em sua execução.

Dada à complexidade do tema, o estudo adotou o pluralismo teórico metodológico. Ao analisar o fenômeno da crise ambiental e sua relação com as águas, particularmente os aquíferos transfronteiriços, utilizou-se como bases principais a teoria da sociedade de risco e a teoria crítica. Essas teorias podem ser entrelaçadas de maneira bastante harmoniosa. A teoria crítica segundo SANTOS $(1999$, p. 197) se "assenta no pressuposto de que a existência não esgota as possibilidades da existência e que, portanto, há alternativas susceptíveis de superar o que é criticável no que existe" enquanto a teoria social do risco alerta justamente para a necessidade de combater à promoção desses efeitos criticáveis da sociedade contemporânea (riscos), efeitos esses que a sociedade perdeu a capacidade de determinar indubitavelmente.

Essa relação entre as teorias se dá pela construção de um diálogo conjunto de autores conhecidos das duas correntes. Por exemplo, no âmbito da teoria crítica, destacaram-se as 
ideias de Enrique Leff, Joan Martinez Allier e Milton Santos, e na teoria do risco as de Ulrich Beck, Anthony Giddens, Paul Slovic e Yvette Veyret.

A perspectiva crítica se fundamentou no desejo da autora de buscar a constante interrogação sobre os discursos estabelecidos no cenário internacional e o seu real comprometimento com uma emancipação social. Por sua vez, a teoria do risco se justificou diante da incerteza que paira sobre as consequências da relação produção e ambiente. Os desdobramentos da crise hídrica atual são incertos. No caso dos aquíferos, a situação se agrava diante do desconhecimento de suas características físicas e de como evoluiriam os conflitos no caso do agravamento da crise ambiental.

Por sua vez, a abordagem do direito internacional vai além da perspectiva clássica positivista, pois as relações internacionais geraram mudanças no "dinamismo da produção de normas jurídicas internacionais" e provocaram "a diversificação das suas formas de surgimento" (AZEVEDO; LIMA, 2009, p.22). A análise deste trabalho vai se centrar na evolução desse direito internacional das águas doces promovida principalmente pela comunidade epistêmica e pelas organizações internacionais intergovernamentais.

Por sua vez, a ordem ambiental internacional foi entendida como um "subsistema em construção - do sistema internacional", que "possui características de um sistema heterogêneo e multipolar" (RIBEIRO, 2001, p. 14 e 35), que se exterioriza por meio de uma série de instrumentos técnicos e políticos destinados a orientar a atuação em matéria ambiental dos atores internacionais. Nas últimas décadas, esses atores estabeleceram diversos mecanismos para promover a temática das águas transfronteiriças na agenda internacional. Esse discurso em muitos casos se revestiu de uma aparência técnica, porém foi marcado por interesses hegemônicos.

As transformações sociais, políticas e econômicas das últimas décadas influenciaram a forma como o direito e a ordem ambiental internacional incorporaram a temática das águas e aquíferos. O direito internacional das águas doces e a ordem ambiental internacional são fenômenos que emergem e expressam as relações internacionais nas últimas décadas; e exteriorizam jogos de poder, política e interesses.

Por fim, adotou-se o estudo de caso, que se deve pautar em um "estudo particular considerado representativo de um conjunto de casos análogos, por ele significativamente representativo" (SEVERINO, 2007, p. 121). Outra razão que justifica essa escolha é o caráter exploratório do trabalho. Diante do número reduzido de pesquisas existentes nessa temática, a observação de um caso concreto é uma boa forma de buscar indícios que possam corroborar ou refutar as hipóteses iniciais. 
A escolha pelo Aquífero Guarani se pautou por diversas razões. A primeira delas foi a busca de um aprofundamento no caso, que já foi objeto de estudo da pesquisadora no mestrado. Soma-se ainda o fato desse aquífero dispor de uma base de dados substancial sobre as suas características, ter sido alvo de diversos projetos de cooperação internacional e ser o único da América Latina que possuiu um acordo internacional. Além disso, a literatura das organizações internacionais e a bibliografia do tema o apontam como um dos principais exemplos de cooperação e governança de aquíferos transfronteiriços. Todos esses fatores justificavam a realização de uma análise mais aprofundada e crítica.

A pesquisa se embasou na análise qualitativa da bibliografia existente sobre o tema e nos diferentes tipos de documentos produzidos pelos atores internacionais: publicações, resoluções, convenções, tratados, acordos, relatórios, modelos de normas provenientes da comunidade epistêmica, projetos conjuntos, entre outros. Realizaram-se ainda entrevistas com especialistas envolvidos na formulação de instrumentos jurídicos internacionais e no Projeto Aquífero Guarani, que contribuíram para verticalizar a busca documental e sua análise. As entrevistas foram abertas e semi-estruturadas, realizadas pessoalmente, por telefone ou conversa direta via internet, e permitiram conhecer diversos pontos de vista sobre a problemática das águas transfronteiriças e aprofundar a busca documental. Essas entrevistas foram feitas ao longo da pesquisa.

\section{Estrutura do Trabalho}

Para alcançar os objetivos deste trabalho, sua estrutura foi dividida em cinco capítulos:

"A crise hídrica e os aquíferos transfronteiriços" contextualiza a problemática das águas subterrâneas e dos aquíferos transfronteiriços como desdobramentos de uma crise ambiental e hídrica causada por uma racionalidade econômica alheia aos seus efeitos socioambientais. Para isso, examinam-se as particularidades dos recursos hídricos subterrâneos, os riscos que os ameaçam e quando eles podem ser considerados um recurso de natureza compartilhada. Aborda-se ainda a relação entre cooperação e conflito e o papel da soberania dos Estados nessa mediação.

Por sua vez, "O direito internacional das águas doces e os aquíferos transfronteiriços" apresenta a formação histórica do direito internacional das águas doces por 
meio de suas diversas fontes e como gradualmente se inseriu a temáticas das águas subterrâneas e dos aquíferos transfronteiriços. São abordados os modelos jurídicos promovidos pelo Instituto de Direito Internacional, pela Associação de Direito Internacional e pela comunidade epistêmica não jurídica, bem como, os instrumentos legitimados pela Assembleia das Nações Unidas: a Convenção das Nações Unidas sobre o Direito relativo aos usos dos cursos de água internacionais para fins distintos da navegação e as águas subterrâneas, também denominada Convenção de Nova York e o projeto de artigos da Resolução ONU 63/124 - o direito internacional dos aquíferos transfronteiriços.

Em “A ordem ambiental internacional e os aquíferos transfronteiriços” se expõem como a ordem ambiental internacional incorporou as águas subterrâneas e os aquíferos transfronteiriços e quais são os principais atores internacionais responsáveis pela inclusão desse tema. Apresenta-se como a água foi tratado nas Grandes Conferências Ambientais (Estocolmo, Rio de Janeiro, Joanesburgo e Rio+20) e nas principais conferências hídricas (Mar del Plata, Dublin e Bonn), bem como se analisa o fenômeno da emergência de novos fóruns de discussão, como o Fórum Mundial da Água e o Fórum Alternativo Mundial da Água, e de novos atores que vão influenciar no processo de governança e gestão das águas.

No capítulo "Aquífero Guarani: a busca por um novo paradigma de cooperação" se objetivou analisar como se deu a dinâmica do processo de cooperação desse aquífero e quais são os desdobramentos decorrentes da intensificação desse processo. São examinadas as experiências promovidas pela comunidade epistêmica, pelas organizações internacionais e pelos Estados, com destaque ao Projeto Sistema Aquífero Guarani e ao Acordo sobre o Aquífero Guarani.

Por fim, se apresentam as conclusões, que trazem uma síntese sobre os avanços, limitações e contradições na atuação do cenário internacional no que tange aos aquíferos transfronteiriços, com particular destaque ao aquífero Guarani. 


\section{CONCLUSÕES}

Os aquíferos transfronteiriços, por muito tempo, foram ignorados pelo direito internacional e pelo sistema internacional que priorizou os recursos hídricos superficiais. Esse tratamento pode ser justificado pelo seu caráter oculto, que prejudicou a constatação da situação de compartilhamento e os atrelou à soberania nacional; ou, ainda, porque as águas subterrâneas não se prestavam aos usos que geraram os principais conflitos internacionais (navegação, demarcação de fronteiras, produção de energia hidroelétrica e pesca).

Dessa forma, a inclusão das águas subterrâneas e dos aquíferos no debate ambiental internacional resulta da percepção mundial do aprofundamento da crise hídrica e da necessidade crescente por água. A crise hídrica tem a sua causa principal na globalização de uma racionalidade econômica dominante que visa à maximização dos lucros no curto prazo e ignora os riscos sociais e ambientais gerados, e é agravada por problemas de governança e gestão. Essa racionalidade econômica tornou essa crise um fenômeno multiescalar, ou seja, suas causas e seu enfrentamento remetem às várias escalas de poder: local, regional, nacional, internacional e global.

A ciência assume um papel fundamental na gestão dos aquíferos transfronteiriços, pois sem ela não é possível revelar suas características físicas, identificar as situações de compartilhamento entre Estados e determinar os riscos e graus de vulnerabilidade. A invisibilidade social desses recursos contribuiu para que os Estados os considerassem um assunto secundário tanto nas políticas nacionais como nas internacionais. Nesse contexto, a comunidade epistêmica e as organizações internacionais têm se mostrado os principais atores na divulgação dos riscos que os ameaçam e no reconhecimento de sua natureza jurídica compartilhada.

A mobilização desses atores tem repercutido nos Estados, que, gradativamente, incorporam a preocupação com as águas subterrâneas e têm assumido alguns compromissos conjuntos para os aquíferos transfronteiriços, que podem versar desde a realização de estudos para a obtenção de dados técnicos, acordos para o intercâmbio de informações e instalação de redes de monitoramento, ou até a instituição de comissões internacionais dedicadas à gestão do aquífero. Essa atuação dos Estados em muitos casos é provocada pela realização de projetos técnicos coordenados por organizações internacionais.

A interdependência da questão ambiental/hídrica e a nova natureza dos riscos exigem processos de cooperação entre os Estados cada vez mais intensos. A soberania é uma peça 
fundamental nesse contexto, pois sem ela não há cooperação. O direito internacional das águas doces e a gestão dos aquíferos transfronteiriços demandam que se supere a interpretação de soberania exercida de forma isolada, dotada apenas de direitos, para uma soberania responsável, que inclua os deveres para com os outros Estados ribeirinhos ou do aquífero e esteja aberta à construção de mecanismos institucionais de cooperação.

O direito internacional tem um papel fundamental na conformação da soberania dos Estados em relação aos recursos hídricos compartilhados. O direito internacional das águas doces já consolidou alguns limites a essa soberania, porém ele ainda está em processo de construção. A ratificação da Convenção de Nova York lhe daria maior legitimidade, porém não encerraria o seu debate. A sociedade de risco trouxe novos desafios, para os quais essa Convenção oferece respostas limitadas (direito humano à água, água virtual, mudanças climáticas). A necessidade de incluir os aquíferos transfronteiriços é um desses desafios, que provocou a atuação de diversas iniciativas, seja de organizações internacionais veiculadas ao quadro da ONU ou da comunidade epistêmica jurídica e não jurídica.

Dos esforços realizados para incluir a dimensão oculta do ciclo hidrológico no direito internacional das águas doces, o mais relevante é a edição da Resolução da ONU 63/124, o direito internacional dos aquíferos transfronteiriços. Esse instrumento ampliou o alcance do direito das águas doces e caracterizou oficialmente esses corpos hídricos como recursos de natureza compartilhada. Além disso, essa Resolução adaptou os princípios constantes na Convenção de Nova York às peculiaridades dos aquíferos, contudo tais inovações não vieram desprovidas de críticas e inquietações.

O principal problema da Resolução 63/124 não é a sua menção ao princípio da soberania como apontaram alguns autores, mas o fato dela não ter buscado se harmonizar com o regime jurídico proposto para as águas subterrâneas na Convenção de Nova York. Dessa forma, criou-se um novo regime jurídico para todos os aquíferos transfronteiriços, mesmo para aqueles que já eram regidos pela Convenção diante da comunicação hidráulica de suas águas com o curso de água internacional.

A abordagem prevista na Resolução $63 / 124$ possui um impacto muito maior na soberania dos Estados do que a da Convenção de Nova York. A interpretação dos princípios é mais restrita e o seu alcance é maior. Por exemplo, a obrigação de não causar dano não se resumiu às atividades relacionadas ao uso do recurso, e a adoção do conceito de aquífero fez com que tanto as águas, como a formação geológica fossem consideradas recursos compartilhados. Cabe resaltar que essa formação geológica em muitos casos irá se confundir com o próprio território dos Estados. Essas distinções de tratamento criaram uma 
sobreposição de regimes jurídicos, que vai atingir a maioria dos aquíferos transfronteiriços. O direito internacional ainda não respondeu qual desses instrumentos vai ser priorizado ou como eles serão compatibilizados.

De todas as formas, a crise hídrica, a interdependência ambiental e seus impactos na humanidade obrigam a que se estreite a cooperação e se busque uma maior integração entre os distintos campos do direito internacional e nacional. $\mathrm{O}$ enfrentamento da crise hídrica exige uma maior articulação entre o direito ambiental internacional, os direitos humanos, direito do comercial internacional, entre outros. Além disso, o direito internacional das águas e do ambiente terá que buscar formas de tornar seus instrumentos mais efetivos e ágeis seja no plano internacional como na transformação dos ordenamentos internos dos Estados.

A cooperação internacional ambiental e hídrica para se materializar demanda que esses temas sejam efetivamente tornados uma prioridade na agenda internacional e nas políticas internas dos Estados, pois o grande desafio dos aquíferos transfronteiriços é articular os interesses nacionais dos distintos atores pertencentes às múltiplas soberanias dos Estados que compõem o aquífero compartilhado. Isto é, os Estados, ao pensarem as políticas hídricas, precisam considerar os seus interesses domésticos e os interesses dos outros Estados do aquífero, os quais são afetados por questões e conflitos internos distintos.

Nesse contexto, o sistema internacional ocupa um papel prioritário na definição de regras e diretrizes para a gestão dos aquíferos. Embora as águas subterrâneas tenham ocupado um papel secundário na ordem ambiental internacional, a preocupação com elas já podia ser encontrada nos instrumentos internacionais elaborados na década de setenta, que contemplavam o problema da falta de informações e dados, a necessidade de estabelecer redes de monitoramento e a busca por formas de geri-las. Apesar disso, foi apenas no final da década de noventa e início de 2000 que as organizações internacionais realmente se dedicaram a promover o conhecimento e a gestão desses recursos de forma decisiva.

$\mathrm{Na}$ década de noventa ocorreu uma profunda alteração na forma como o sistema internacional concebia o problema da crise hídrica. De uma questão prioritariamente dos Governos, a água se tornou um problema dos mercados, esse entendimento possibilitou a inserção de instituições econômicas e agentes privados na formulação das diretrizes internacionais que norteariam a gestão das águas e aquíferos, incluindo os transfronteiriços.

Esse fenômeno vai se revelar na criação de uma série de novas organizações internacionais de fomento à temática hídrica, novas linhas de financiamento e a promoção de uma série de eventos e publicações sobre água enaltecendo a necessidade da governança e da 
gestão integrada dos recursos hídricos, como formas de proporcionar uma utilização dos recursos hídricos pautada pelo desenvolvimento sustentável.

Dessa forma, a temática ambiental e hídrica se configuraria na escala internacional por uma série de conceitos vagos e incertos, tais como desenvolvimento sustentável, governança e gestão integrada dos recursos hídricos. O potencial desses conceitos em promover uma verdadeira transformação na racionalidade econômica e enfrentar a crise hídrica é discutível. Por um lado esses conceitos ampliaram consideravelmente o debate sobre a relação entre meio ambiente e desenvolvimento, o formato e funcionamento dos sistemas institucionais responsáveis pela gestão hídrica, e os tipos de ações que fundamentam essa gestão. Por outro, legitimaram um discurso hegemônico que visa justamente aprofundar a racionalidade econômica dominante, contribuindo para a consolidação do fenômeno da irresponsabilidade organizada, por meio de uma estrutura pseudo-democrática, que ignora o contexto de profunda assimetria entre os Estados e os atores.

Ou seja, a construção da governança das águas e a gestão dos recursos hídricos abarcam as mais distintas experiências. No caso dos aquíferos transfronteiriços, apesar dos esforços internacionais, a construção de uma governança internacional capaz de levar adiante uma gestão integrada dos aquíferos enfrenta dificuldades. Porém, sem dúvida, o sistema internacional e os seus atores têm sido os principais responsáveis por incentivar os Estados a incorporarem esse tema em suas agendas, ainda que com limitações.

$\mathrm{O}$ caso do Aquífero Guarani pode ser bastante ilustrativo. A cooperação internacional estabelecida entre Argentina, Brasil, Paraguai e Uruguai para o Aquífero Guarani e a assinatura de seu respectivo acordo são fruto desse contexto internacional que tem promovido à temática das águas subterrâneas. O modelo de cooperação adotado no Guarani vai replicar a ordem ambiental e o direito internacional das águas doces e expor seus avanços, limitações e contradições.

A cooperação se marcou por três fases distintas, sendo que a mais intensa foi justamente aquela que contou com a ostensiva participação das organizações internacionais. Foi apenas com o ingresso dessas organizações, por meio da execução do Projeto Sistema Aquífero Guarani, que os Estados decidiram tomar algum tipo de providência em relação a esse aquífero. Essa ação de cooperação se desdobrou em novas leis e regulamentos nacionais e um acordo internacional sobre o tema, bem como em algumas iniciativas gerenciais, que estão longe de estabelecer uma gestão eficiente dos aquíferos, mas significam um passo importante e enaltecem a gestão local. 
Ainda que o fluxo hídrico do Aquífero seja compartilhado somente em uma pequena porção do aquífero que coincide com parte das zonas de fronteira entre os países, a assinatura do Acordo sobre o Aquífero Guarani é importante, pois representa uma continuidade ao processo de cooperação e dá visibilidade às águas subterrâneas e aos aquíferos dos países e da América do Sul. Além disso, pode estimular a cooperação e gestão de outros aquíferos.

A atuação internacional na área do aquífero pode ter contribuído para a assinatura do Acordo sobre Aquífero Guarani de distintas formas. Estimulou os Estados a adotarem uma postura pautada pela diplomacia preventiva. Os investimentos realizados e o envolvimento de importantes organizações internacionais criou uma pressão internacional pela continuidade dos esforços de cooperação. Ou ainda, diante do destaque que esse aquífero ganhou, os Estados quiseram reafirmar sua soberania perante o aquífero, garantindo-o como uma reserva exclusiva dos quatro países. Outro argumento que pode ser defendido é que a celebração do acordo pode ter sido uma estratégia dos Estados para apaziguar os desentendimentos causados pela controvérsia regional sobre as papeleiras.

Dessa forma, percebe-se que esse acordo pode ter sido fruto de múltiplas variáveis. Porém, independente, do que motivou sua assinatura, ele é um marco jurídico internacional para a região, pois representou o primeiro tratado específico para as águas subterrâneas realizado na América Latina e o único do mundo assinado em um contexto de ausência de conflitos ou degradação.

Ao que pese tais atributos, o acordo possui uma série de lacunas que podem prejudicar consideravelmente sua aplicação. A previsão de uma Comissão para o aquífero é louvável, porém não há indícios de como se daria sua constituição ou quais seriam seus poderes e papeis no processo de cooperação. Além disso, não há qualquer menção às áreas de recarga, que efetivamente são os locais onde poderiam ocorrer os conflitos transfronteiriços, e na iminência de um conflito não se estabeleceu um sistema de solução de controvérsias. Outra inquietação diz respeito a quando o Acordo será ratificado. Já se passaram dois anos e nenhum país deu sinais de pretender ratificá-lo. A julgar pelos tratados ambientais assinados pelo Mercosul, essa espera pode ser longa. Portanto, percebe-se que há uma significativa agenda de trabalho para os países.

A gestão da maioria dos aquíferos transfronteiriços na escala internacional, incluindo o caso do aquífero Guarani, está no melhor caso em sua infância. O conhecimento gerado pelos projetos conduzidos pelas organizações internacionais e pela comunidade epistêmica contribui para demonstrar a importância dos aquíferos e a necessidade de incorporá-los na gestão nacional e internacional. Porém, os Estados enfrentam dificuldades em transformar 
esse conhecimento em iniciativas concretas de cooperação para a gestão conjunta ou aperfeiçoamento de suas políticas internas. Ainda que na maioria dos casos não questionem o cerne do problema (a racionalidade econômica dominante), os conceitos de governança e gestão integrada dos recursos hídricos têm incentivado o processo de cooperação e a criação de arranjos jurídicos conjuntos. A busca por ações de cooperação entre os Estados pode contribuir para a elaboração de políticas de uso e proteção das águas subterrâneas, promovendo melhorias na sua gestão. 


\section{REFERÊNCIAS}

ABDELRHEM, I. M.; RASHID, K; ISMAIL A. Simulation of Groundwater Level at Murzuk Basin Due to Great Man-Made River Project-Libya. European Journal of Scientific Research, v. 26, n. 4, p. 522-531, 2009.

ACCUVAL. Bottled Water: Quenching Thirst by the Gallon. jun. 2010. Disponível online $\mathrm{em}$ : http://www.accuval.net/insights/industryinsights/detail.php?ID=138. Acesso em: 23 jan. 2011.

ACCIOLY, H; SILVA, G. E. N.; CASELlA, P. B. Manual de Direito Internacional Público. 17 ed. São Paulo: Saraiva, 2009.

ACSELRAD, H. As práticas espaciais e o campo dos conflitos ambientais. In ACSELRAD, H. (ORG.) Conflitos Ambientais no Brasil. Rio de Janeiro: Relume Dumará, Fundação Heinrich Böll, 2004. p. 13-35.

ACSELRAD, H. Vulnerabilidade ambiental, processos e relações. In: II ENCONTRO NACIONAL DE PRODUTORES E USUÁRIOS DE INFORMAÇÕES SOCIAIS, ECONÔMICAS E TERRITORIAIS, 2, Rio de Janeiro, 2006. Comunicação. Rio de Janeiro: FIBGE, 2006. Disponível online: http://www.justicaambiental.org.br/projetos/clientes/ noar/noar/UserFiles/17/File/VulnerabilidadeAmbProcRelAcselrad.pdf. Acesso: 23 fev 2012.

ACSELRAD, H. Introdução. In: ACSELRAD, H. (org.). Cartografias sociais e território. Rio de Janeiro: Universidade Federal do Rio de Janeiro, Instituto de Pesquisa e Planejamento Urbano e Regional, 2008. p. 9 - 11.

ACTION PLAN FOR THE HUMAN ENVIRONMENT. United Nations Conference on the Human Environment, 1972. Disponível online: http://fds.oup.com/www.oup.co.uk /pdf/bt/cassese/cases/part3/ch17/1204.pdf. Acesso: 22 jul. 2012.

AGENDA 21 GLOBAL. Traduzida para o português. 1994. Disponível online: http://www.ambiente.sp.gov.br/agenda21.php. Acesso: 23 ago. de 2012.

ALIER, J. M. O ecologismo dos pobres: conflitos ambientais e linguagens de valoração. São Paulo: Contexto, 2007.

ALKER, M. The Lake Chad Basin Aquifer System. A case study for the research project "Transboundary groundwater management in Africa". Bonn: German Development Institute, 2008. Disponível online: http://www.isn.ethz.ch/isn/Digital-Library/ 
Publications/Detail/?ots591=cab359a3-9328-19cc-a1d2-8023e646b22c\&lng=en\&id $=103364$. Acesso: 4 jun 2011

ALLAN, J.A. Fortunately there are substitutes for water otherwise our hydro-political futures would be impossible. In: Overseas Development Administration. Priorities for water resources allocation and management. London: ODA, 1993. p. 13-26.

ALlAN, J. A T.; MIRUMACHI, N. Why negotiate? Asymmetric Endowments, Asymetric Power and the Invisible Nexus of Water, Trade and Power that brings apparent water security. In: EARLE, A.; JÄGERSKOG, A.; OJËNDAL, J. (Orgs.). Transboundary Water Management: Principles and Practice. London: Earthscan, 2010.p.13-26.

ALLEY, W. M. The Importance of Monitoring to Groundwater Management. In: HOLLIDAY, L.; MARIN, L.; VAUX, H (eds.). Sustainable Management of Groundwater in Mexico. Proceedings Workshop Strengthening Science-Based Decision Making in Developing Countries. Washington, D.C: The National Academies Press, 2007. p. 76-85. Disponível online: http://www.nap.edu/openbook.php?record_id=11875\&page=76. Acesso: 3 jan. 2012.

AMARAL JÚNIOR, A. Manual do Candidato: Noções de Direito e Direito Internacional. $3^{\text {a }}$ ed. ampliada e atualizada. Brasília : Funag - 2008.

AMER, S. E. D. The law of water. historical record. Options Méditerranéennes, Sér. a /n031, 1997, Séminaires Méditerranéens. p. 381-390. Disponível online: http://ressources.ciheam.org/om/pdf/a31/CI971551.pdf. Acesso: 4 jun. 2010.

AMORIN, J. A. A. Direito das Águas: o regime jurídico da água doce no direito internacional e no Direito Brasileiro. São Paulo: Lex Editora, 2009.

ARAUjO, L. M; FRANÇA, A. B., POTTER, P. E. Aqüífero Gigante do Mercosul no Brasil, Argentina, Paraguai e Uruguai: mapas hidrogeológicos das formações Botucatu, Piramboia, Rosário do Sul, Buena Vista, Missiones, Tacuarembó. Curitiba: Universidade Federal do Paraná, Biblioteca de Ciência e Tecnologia e Petrobras, 1995.

ATTILI, S. Israel and Palestine: Legal and Policy Aspects of the Current and Future Joint Management of the Shared Water Resources. The Negotiation Support Unit. Ramallah, West Bank, June 2004. Disponível online: http://www.nad-plo.org/userfiles/file/Reports/sharedwater.pdf. Acesso: 20 fev. 2010. 
AZEVEDO, A.; LIMA; G. Construção do conceito de efetividade no Direito. In: BARROSPlatiau, A. F.; VARELlA, M. D. A efetividade do Direito Internacional Ambiental. Brasília: UNICEUB; UNITAR e UNB, 2009. p. 8-24.

BARBÉ, E. Relaciones Internacionales. Madrid: Editorial Tecnos, 1995.

BARBERIS, J.A. International ground water resources law. Food and Agricultural Organization Legislative Study n40. Rome: FAO,1986.

BARREIRO, A.; DAVYT, A. Cincuenta años de la Oficina Regional de Ciencia y Tecnología para América Latina y el Caribe de la Organización de las Naciones Unidas para la Educación, la Ciencia y la Cultura (ORCYT/UNESCO): Un análisis histórico de la cooperación en la región. 1999. Disponível online: http://www.unesco.org.uy/shs/fileadmin/templates/shs/archivos/orcyt50.pdf. Acesso 7 de setembro de 2012.

BASTOS, C. R. Curso de Direito Constitucional. 22. ed. São Paulo: Saravia, 2001.

BARROS-PLATIAU, A. F. A Política Externa Ambiental: do desenvolvimentismo ao desenvolvimento sustentável. In: ALTEMANI, H.; LESSA, A. C. (Orgs.). Relações Internacionais do Brasil: temas e agendas. São Paulo: Saraiva, volume 2, p. 251-281, 2006.

BEAUMONT, P. The 1997 UN Convention on the Law of Non-Navigational Uses of International Watercourses: Its Strengths and Weaknesses from a Water Management Perspective and the need for new workable guidelines. Water Resources Development, v. 16, n. 4, p. 475-495, 2000.

BECK, U. Ecological Politics in an Age of Risk. 2ed. Cambridge: Polity Press, 2002

BECK, U. La sociedad del riesgo: Hacia una nueva modernidad. Barcelona: Ediciones Paidós Ibérica, 2006.

BECK, U. La sociedad del riesgo mundial: Em busca de la seguridad perdida. Traducción de Rosa S. Carbó. Barcelona: Ediciones Paidós Ibérica, 2008.

BENVENISTI, E. Collective Action in the utilization of shared freshwater: the challenge of International Water Resources Law. The American Journal of International Law, v. 90, n. 3, p. 384-415, jul. 1996. 
BEHRMANN, C.; STEPHAN, R. M. The UN Watercourse Convention and the draft articles on transboundary aquifers: the way ahead. Pre-proceedings of ISARM international conference, "Transboundary aquifers: challenges and new directions" [CD-ROM]. UNESCO, 6-8 December 2010. Paris: UNESCO.

BIRNIE, P.; BOYLE, A.; REDGWELL, C. International Law and the Environment. 3ed. New York: Oxford University press, 2009.

BISWAS, A. K. United nations water conference action plan. International Journal of Water Resources Development, v. 4, n. 3, p. 148 - 159, 1988.

BISWAS, A. K. Integrated Water Resources Management: Is It Working?', International Journal of Water Resources Development, v. 24, n.1, p. 5 - 22, 2008.

BODANSKY, D. M. Customary (and not so customary) international Environmental Law. Indiana Journal of Global Legal Studies, v. 3, n. 1, Symposium: International Environmental Laws and Agencies: The Next Generation, p. 105-119, 1995. Disponível online: $\quad \underline{\text { http://digitalcommons.law.uga.edu/cgi/viewcontent.cgi?article=1511\&context }}$ =fac_artchop. Acesso: 5 mar. 2010

BOGDANOVIC, S.; BOURNE, C.; BURCHI, S; WOUTERS, P. Water Resources Committee Report Dissenting Opinion. ILA Berlin Conference, 2004. Disponível online em: http://www.internationalwaterlaw.org/documents/intldocs/ila_berlin_rules_dissent.html. Acesso: 20 jan. 2012.

BORGHETTI, N.; BORGHETTI, J. R.; ROSA, E. F. F. Aquífero Guarani - A verdadeira integração dos países do Mercosul. Curitiba: Maxigráfica, 2004.

BORGHETTI, N.; BORGHETTI, J. R.; ROSA, E. F. F. A integração das águas: revelando o verdadeiro aquífero Guarani. Curitiba: Edição da autora, 2011.

BOURNE, C. The International Law Association's contribution to International Water Resources Law. Natural Resources Journal, v. 36, p.155-216, 1996.

BROWNLIE, I. Principles of public international Law. 5 ed. New York: Oxford University Press, 1998.

BRZEZINSKI, M. L. N. L. Direito Internacional em matéria de água doce: conteúdo, formas e efetividade. 2011. $382 \mathrm{f}$. Tese (Doutorado em Direito) - Faculdade de Direito, Universidade do Estado do Rio de Janeiro, Rio de Janeiro, 2011. 
BRZEZINSKI, M. L. L. N. Direito Internacional da Água Doce: fontes, regimes jurídicos e efetividade. Curitiba: Juruá, 2012.

BUCHEB, J. A. Unitização no Brasil - Questões Controversas. Rio Oil \& Gas Expo Conference 2008, realizada no período de 15 a 18 de setembro de 2008, no Rio de Janeiro. Instituto Brasileiro de Petróleo, Gás e Biocombustíveis - IBP.

BULLARD, R. Enfrentando o racismo ambiental no século XXI. In: ACSELRAD, H.; HERCULANO, S; PADUA, J. A. Justiça ambiental e cidadania. Rio de Janeiro: Relume Dumará: Fundação Ford, 2004, p. 41-66

BURKE, J.J. Groundwater for irrigation: productivity gains and the need to manage hydroenvironmental risk. In: LLAMAS, R; CUSTODIO, E (eds.) Intensive use of groundwater: challenges and opportunities. Abingdon, UK: A. A. Balkema, 2002. p. 59-92.

BURCHI, S.; MECHLEM, K. Groundwater in international law Compilation of treaties and other legal instruments. Rome: UNESCO and FAO, 2005.

BUZAN, B., WÆVER, O.; WILDE, J. Security: A New Framework for Analysis. London: Lynne Rienner Publishers. 1998.

CAFLISCH, L. Regulation of the uses of international watercourses. In: SALMAN, S; CHAZOURNES, L. B. (Eds.), International Watercourses - Enhancing Cooperation and Managing Conflict. Washington, DC: World Bank Technical Paper n. 414. 1998. p. 3-16.

CAMPOS, H. C. N. S. Mapa Hidrogeológico del Acuífero Guarani. In: I CONGRESSO MUNDIAL INTEGRADO DE ÁGUAS SUBTERRÂNEAS, 2000, Fortaleza. ABAS ALHSUD - IAH (CD-ROM). Anais... paper 220. Fortaleza: ABAS - ALHSUD - IAH, 2000. Disponível online: http://aguassubterraneas.emnuvens.com.br/asubterraneas/ article/viewFile/23525/15607. Acesso: 7 set. 2012.

CANOTILHO, J. J. G. O Regime Jurídico Internacional dos Rios Transfronteiriços. Coimbra: Coimbra Editora, 2006.

CAP-NET, PNUD. Planejamento para a Gestão Integrada de Recursos Hídricos. Manual de Capacitação e Guia Operacional. Training Material CD. 2006. 
CASTRO, D. Tratamento jurídico internacional da água e desenvolvimento sustentável. 2009. Dissertação (Mestrado em Direito Internacional) - Faculdade de Direito, Universidade de São Paulo, São Paulo, 2009. Disponível em: $<$ http://www.teses.usp.br/teses/disponiveis/2/2135/tde-03062011-110124/>. Acesso: 30 jun 2012.

CAUBET, C. G. As grandes manobras de Itaipu: energia, diplomacia e direito na Bacia do Prata. São Paulo: Editora Acadêmica, 1991.

CAUBET, C. G. A água doce nas relações internacionais. Barueri, SP: Manole, 2006.

CERVO, A. L. Sob o signo neoliberal: as relações internacionais da América Latina. Rev. bras. polít. int., Brasília, v. 43, n. 2, dec. 2000. Disponível online: $<$ http://www.scielo.br/scielo.php?script=sci_arttext\&pid=S0034-73292000000200001 \&lng=en\&nrm=iso $>$. Acesso: 27 jul. 2012.

CLEARY, R., Águas Subterrâneas. In: ASSOCIAÇÃO BRASILEIRA DE RECURSOS HÍDRICOS ENGENHARIA HIDROGEOLÓGICA. Coleção ABRH de Recursos Hídricos. Rio de Janeiro: Editora da UFRJ, 1989.

CHINA-WIRE. China introduces first national plan on groundwater pollution control. Xinhua, october 29th, 2011 a. Disponível online: http://china-wire.org/?p=16497. Acesso: 24 fev 2012.

CHINA-WIRE. Poisoned Wells. November 04th, 2011b. Global Times. Disponível online: http://china-wire.org/?p=16618. Acesso: 24 fev. 2012.

CISNEROS, B. J.; TUNDISI, J. G. Diagnóstico del agua en las Américas. Red Interamericana de Academias de Ciencias. México: Foro Consultivo Científico y Tecnológico, 2012. Disponível online: $\underline{\text { http://www.foroconsultivo.org. } \mathrm{mx} /}$ libros_editados/agua_2012/mexico.pdf. Acesso: jun. 2012.

CONCA, K. Contentious Transnational Politics and Global Institution Building. Cambridge, MA: Massachusetts Institute of Technology, 2006.

CUSTODIO, E. Aquifer Overexplotation: what does it mean. Hydrogeology journal, v.10, n.2, p. $257-277,2002$. 
DABROWSKI, J. M.; MURRAY, K.; ASHTON, P. J.; LEANER, J. J. Agricultural impacts on water quality and implications for virtual water trading decisions. Ecological Economics, v.68, n. 4, p.1074-1082, 2009

D'AMATO, A. Trashing customary international law. American Journal of International Law, v. 101, 1987. Disponível online: http://anthonydamato.law.northwestern.edu/ Adobefiles/a87a-trashing.pdf. Acesso 14 jan. 2012.

DELLAPENNA, J.W. The Berlin Rules on Water Resources: The new paradigm for International Water Law: Examining the Confluence of Environmental and Water Concerns. In: Proceeding of the World Environmental and Water Congress, 21-25 May 2006 Omaha, NE; USA: American Society of Civil Engineers, 1-5. 2006.

DELLAPENNA, J. W. The customary law applicable to internationally shared groundwater. Water International, v. 36, n. 5, p. 584-594, 2011.

DELLI PRISCOLI, J. e WOLF, A. T. Managing and transforming water conflicts. New York: Cambridge University Press, 2009.

DINIZ, E. Crise, reforma do Estado e governabilidade. Brasil, 1985-1995. Rio de Janeiro: Fundação Getúlio Vargas, 1999. 228p.

DONAHUE, J. M.; IRENE J. KLAVER. Sharing Water Internationally, Past, Present and Future-Mexico and the United States. Southern Rural Sociology, v. 24, p.1, p. 7- 20, 2009.

DURHAM, B.; RINCK-PFEIFFER, S.; GUENDERT, D. Integrated Water Resource Management through reuse and aquifer recharge. Desalination, v.152, n. 1-3, p. 333-338, 2003 .

EARLE, A.; JÄGERSKOG, A.; OJËNDAL，J. Introduction: Setting the scene for transboundary water manangement approaches. In: EARLE, A.; JÄGERSKOG, A.; OJËNDAL, J. (Orgs.). Transboundary Water Management: Principles and Practice. London: Earthscan, 2010. p. 1-10.

EATON, A.; RAMIREZ, L. M.; HAGHANI, A. The Erin Brockovich Factor- Analysis of Total and Hexavalent Chromium in Drinking Waters. MWH Laboratories Pasadena. Nashville, TN: AWWA WQTC, 2001. 
ECKSTEIN, Y.; ECKSTEIN, G. E. Transboundary Aquifers: Conceptual Models for Development of International Law. Ground water, v. 3, n. 5, p. 679-690, setember-october, 2005.

ECKSTEIN, G. E. Hydrogeological perspective of the status of ground water resources, under the UN Watercourse Convention. Columbia Journal of Environmental Law, v.30, 2005. Disponível online: http://ssrn.com/abstract=899142. Acesso: 23 jul 2011.

EHRLICH, P. R. The population bomb. New York: Buccaneer Books, 1968.

EHRLICH, P. R.; EHRLICH , A. H.. The Population Bomb Revisited. Electronic Journal of Sustainable Development, v. 1, n. 3, p.63-71, 2009. Disponível online: http://www.populationmedia.org/wp-content/uploads/2009/07/Population-Bomb-RevisitedPaul-Ehrlich-20096.pdf. Acesso: 02 maio 2012.

EL-FADEL, M., QUBA'A, R., EL-HOUGEIRI, N., HASHISHO, Z. AND JAMALI, D. The Israeli Palestinian Mountain Aquifer: a case study in ground water conflict resolution. Journal of Natural Resources \& Life Sciences Education, v.30, p. 50-61, 2001.

ESPEY, M; TOWFIQUE, B. International bilateral water treaty formation. Water Resources Research, v. 40, W05S05. 2004.

EVASO, A.; BITTENCOURT JR, C.; VITIELLO, M. A.; NOGUEIRA, S. M.; RIBEIRO, W. C. Desenvolvimento sustentável: mito ou realidade? Terra Livre, São Paulo, v. 11, p. 91$101,1996$.

FORUM ALTERNATIF MONDIAL DE L'EAU - FAME. Declaration of the participants at the Alternative World Water Forum. Marseille 14 - 17 de março de 2012. Disponível online: http://www.fame2012.org/en/2012/05/13/final-declaration/. Acesso: 25 set. 2012.

FEITELSON, E. Impediments to the management of shared aquifers: A political economy perspective. Hydrogeology Journal, v.14, n. 3, p.319-329, 2006.

FINUCANE, M. L.; SLOVIC, P.; MERTZ, C.K.; FLYNN, J.; SATTERFIELD, T. A. Gender, race, and perceived risk: the 'white male' effect. Healthy Risk \& Society, v. 2, n. 2, p. 159-172, 2000. Disponível online: http://www.sfu.ca/medialab/ archive/2011/426/readings/Other/finucane $\% 202000 \% 20$ white $\% 20$ male $\% 20$ effect.pdf. Acesso: 22 jan. 2012. 
FIORI, J. L. A governabilidade democrática na nova ordem econômica. Coleção Documentos. Série Teoria Política, nº 13. São Paulo: IEA-USP, 1995.

FOOD AND AGRICULTURE ORGANIZATION - FAO. Survey and Evaluation of Available Data in Shared Water Resources in the Gulf States and the Arabian Peninsula. Published for the Secretariat of the Congress of Ministers of Agriculture of the Gulf States and the Arabian peninsula, 3 volumes, FAO, Rome. 1980.

FOSTER, S.; HIRATA, R. Groundwater pollution risk evaluation: the methodology using available data. Lima: CEPIS, 1988.

FOSTER, S; HIRATA, R. Determinación del riesgo de contaminación de aguas subterráneas. Una metodologia basada en datos existentes. CEPIS. Technical Report (OPS OMS - HPE), Lima, Peru, 1991.

FOWLER, M.; BUNCK, J. M. Law, Power, and the Sovereign State: the evolution and application of the concept of sovereignty. University Park: Pennsylvania State University Press, 1995.

FUENTES, X. The utilization of international groundwater in General International Law. In: Goodwin-Gill, G. S.; TALMON, S. The Reality of International Law: Essays in Honor of Ian Brownlie., Oxford: Oxford University Press. 1999. p.177-198.

GEARY, M.. O debate sobre a fábrica de celulose no Rio Uruguai: um conlfito ecológico distributivo. GEOUSP: espaço e tempo, v. 31, jul. 2012. Disponível em: http://citrus.uspnet.usp.br/geousp/ojs-2.2.4/index.php/geousp/article/view/601. Acesso em: 28 Set. 2012.

GERSEN, J. E; POSNER, E. A. Soft law: lessons from congressional practice. Stanford Law Review, v .61, n.3, p. 573-628, 2008. Disponível online: http://www.stanfordlawreview.org/print/article/soft-law-lessons-congressional-practice.

Acesso em: 24 jun. 2011.

GALILI, E.; NIR, Y. The submerged Pre-Pottery Neolithic water well of Atlit-Yam, northern Israel, and its palaeoenvironmental implications. Holocene, v.3, n.3, p. 265-270, 1993.

GIDDENS, A. Mundo em descontrole: o que a globalização está fazendo de nós. 6 ed. Rio de Janeiro: Record, 2007. 
GLEICK, P. H. Water, war and peace in the Middle East. Environment: science and policy for sustainable development, v. 36, n.3, p. 6-42, 1994.

GLENNON, R. Water follies: groundwater pumping and the fate of America's freshwaters. Washington, D.C.: Island Press, 2002.

GLOBAL WATER PARTNERSHIP. Integrated Water Resources Management. TAC Background Papers No. 4. GWP. Stockholm, Sweden. 2000. Disponível online: http://www.gwp.org/Global/GWP-CACENA_Files/en/pdf/tec04.pdf. Acesso: 3 nov. 2010.

GLOBAL WATER PARTNERSHIP. Dialogue on Effective Water Governance: learning from the dialogues. GWP. Stockholm, Sweden, 2002. Disponível online: http://www.waterinfo.gr/pages/GWPfolderGovernance.pdf. Acesso em: 3 nov. 2010.

GOLDBLAT, D. Teoria Social e Ambiental. Lisboa: Instituto Piaget. 1996.

GUNN, E. L. Governing shared groundwater: the controversy over private regulation. The Geographical Journal, v.15, n. 1, p.39-51, 2009.

GRASA, R. Los conflictos verdes: su dimensión interna e internacional. Revista Ecologia Política, Barcelona, no 8. p. 25-40,1994.

GRUPO DE ESTUDOS POLÍTICOS EUROPEUS. Agrupamento Europeu de Cooperação Territorial. União Europeia, Comitê das Regiões, Bruxelas, 2007. Disponível online em: http://cor.europa.eu/en/archived/ documents/9e2c34ac-504c-4815-bb3f-dd9710bf5167.pdf. Acesso em: 22 jan. 2012.

HAAS P. M. Introduction: epistemic communities and international policy coordination. International Organization, v.46, n 1, p. 1-35, 1992.

HALL, R. E. Transboundary groundwater management:Opportunities under international law for groundwater management in the United States-Mexico border region. Arizona Journal of International and Comparative Law, v.21, n.3, p. 873-911, 2004. Disponível online: http://www.ajicl.org/AJICL2004/vol213/Hall\%20 formatted.pdf. Acesso: 22 jan. 2010.

HAMNER, J.; WOLF, A. Patterns in International Water Resource Treaties: The Transboundary Freshwater Dispute Database. Colorado Journal of International Environmental Law and Policy. 1997 Yearbook, 1998. Disponível online: http://www.transboundarywaters.orst.edu/publications/patterns/. Acesso: 3 jan. 2010. 
HARDIN, G. The Tragedy of the Commons. Science, v 162, p. 1243-1248, v.13, 1968.

HASSENFORDER, E; NOURY, B.; DANIEL, P. GUARANI BASIN: Environmental Protection and Sustainable Development of the Guarani Aquifer System Project (GAS). Case Study n ${ }^{\circ}$ 1. 6th World Water Forum. March 2012.

HAYTON, R.D.; UTTON, A.E. Aguas subterráneas transfronterizas: anteproyecto de Tratado "Bellagio". 1989. Tradução Carmen L. de Campoy, Raquel L.D. Barbuzza. Disponível em: <http://www.sg-guarani.org>. Acesso em: 05 out. 2004.

HEWSON, M.; SINCLAIR, T.J. The emergence of Global Governance Theory. In: HEWSON, M.; SINCLAIR, T. J. Approaches to Global Governance Theory. Albany, State University of New York Press, 1999, p. 3-22.

HOFBAUER. J. A. The Principle of Permanent Sovereignty over Natural Resources and Its Modern Implications. 2001. 109f. Dissertação (Dissertação em Direito) - Faculty of Law, University of Iceland, Reykjavík, 2009.

HOCHSTETLER, K. Fading green? Environmental politics in the MERCOSUR Free Trade Agreement. Latin American Politics and Society, v. 45, n.4, p. 1-33, 2003.

HOCHSTETLER, K.. Race to the middle: environmental politics in the MERCOSUR Free Trade Agreement. In: DAUVERGNE, P. Handbook of global environmental politics. Cheltenham: Edward Elgar, 2005. p. 348-361.

HOCHSTETLER, K.; CLARK, A. M.; FRIEDMAN, E. J. Sovereignty in the Balance: Claims and Bargains at the UN Conferences on the Environment, Human Rights, and Women. International Studies Quarterly, v. 44, n.4, p 591-614, 2000.

HOEKSTRA, A. Y. The Global Dimension of Water Governance: Nine Reasons for Global Arrangements, in Order to Cope with Local Water Problems. Research Report Series No. 20. Delft: UNESCO - IHE, 2006.

HUSSAM, A.; AHAMED, S.; MUNIR, A.K. Arsenic filters for groundwater in Bangladesh: Toward a sustainable solution. The Bridge: Technologies for Clean Water, v. 38, n.3, p. 14$23,2008$.

INSTITUTO BRASILEIRO DE GEOGRAFIA E ESTATÍSTICA - IBGE. Pesquisa Nacional de Saneamento Básico 2008. Tabela 28 - Municípios, total e com serviço de 
abastecimento de água por rede geral de distribuição, por tipo de captação, segundo as Grandes Regiões e as Unidades da Federação - 2008. Rio de Janeiro: IBGE, 2010. Disponível online: http://www.ibge.gov.br/home/estatistica/populacao/condicaodevida/pnsb2008/default tabzip_abast_agua.shtm. Acesso em: 23 jun. 2010.

INTERNATIONAL ATOMIC ENERGY AGENCY - IAEA. Regional Strategic Action Programme For the Nubian Sandstone Aquifer System. Final Report, 26 January 2012. Disponível online: http://iwlearn.net/iw-projects/2020/reports/regional-strategic-actionprogramme-for-the-nubian-sandstone-aquifer-system/view. Acesso em: 5 jun. 2012.

INTERNATIONAL CENTRE FOR THE SETTLEMENT OF INVESTMENT DISPUTES (ICSID). Case No. ARB(AF)/05/1 (Bayview Irrigation District et al. v. United Mexican States). June 19, 2007. Disponível online: https://icsid.worldbank.org ICSID/FrontServlet?requestType $=$ CasesRH\&actionVal=showDoc\&docId=DC653_En\&caseI d=C246. Acesso: 23 nov. 2011.

INTERNATIONAL COURT OF JUSTICE - ICJ. The Corfu Channel Case (Reino Unido v. Albania). Reports of Judgments, Advisory Opinions and Orders. Judgment April 9th, 1949. Disponível online: http://www.icj-cij.org/docket/files/1/1645.pdf. Acesso: 22 out. 2011.

INTERNATIONAL COURT OF JUSTICE - ICJ. Barcelona Traction, Light and Power Company. Limited Judgment. I.C.J. Reports 1970. Disponível online: http://www.icjcij.org/docket/files/50/5387.pdf. Acesso em: 05 dez. 2011.

INTERNATIONAL COURT OF JUSTICE - ICJ. Case concerning the military and paramilitary activities in and against Nicaragua (Nicaragua v. United States of America). Judgment of 27 June 1983. Disponível online em: http://www.icjcij.org $/$ docket $/$ index.php? $\mathrm{sum}=367 \&$ code $=$ nus $\& p 1=3 \& p 2=3 \&$ case $=70 \& \mathrm{k}=66 \& p 3=5$. Acesso em: 23 out. 2010 .

INTERNATIONAL COURT OF JUSTICE - ICJ. Case concerning the GabcikovoNagymaros Project (Hungary v. Slovakia). Judgment of 25 September 1997. Disponível online: http://www.icj-cij.org/docket/files/92/7375.pdf. Acesso em: 23 nov. 2011.

INTERnATIONAL COURT OF JUSTICE - ICJ. Pulp Mills on the River Uruguay (Argentina $v$. Uruguay). Summary of the Judgment of 20 April 2010. Disponível online: http://www.icj-cij.org/docket/files/135/15895.pdf. Acesso: 20 nov. 2011.

INTERNATIONAL COURT OF JUSTICE - ICJ. Certain Activities carried out by Nicaragua in the Border Area (Costa Rica v. Nicaragua). Request for the indication of provisional measures. Summary of the Order of 8 March 2011. Disponível online: http://www.icj-cij.org/docket/files/150/16342.pdf. Acesso: 20 nov. 2011. 
INTERNATIONAL HYDROLOGICAL PROGRAMME - IHP. Internationally Shared (Transboundary) Aquifer Resources Management: Their significance and sustainable management. IHP-VI, IHP Non Serial Publications in Hydrology. Paris: UNESCO, 2001.

INTERNATIONAL LAW ASSOCIATION. The Helsinki Rules on the Uses of the Waters of International Rivers, Helsinki, 1966. Disponível online: http://www.fao.org/docrep/005/W9549E/w9549e08.htm\#bm08..4.10.1. Acesso em: 22 jan. 2011.

INTERNATIONAL LAW ASSOCIATION. Rules on International Groundwaters - Seoul, 1986. Disponível online: http://www.fao.org/docrep/005/W9549E/w9549e08 .htm\#bm08..4.10.10. Acesso em: 22 jan. 2011

INTERNATIONAL LAW ASSOCIATION. The Berlin Rules on Water Resources. Final Conference Report Berlin 2004. Disponível online: http://www.ilahq.org/en/committees/index.cfm/cid/32. Acesso: 14 jan. 2011.

INTERNATIONAL LAW COMISSION. Draft articles on the law of the non-navigational uses of international watercourses and commentaries thereto and resolution on transboundary confined groundwater. Yearbook of the International Law Commission, $v$. II, Part Two, 1994. Disponível online: http://untreaty.un.org/ilc/texts/ instruments/english/commentaries/8_3_1994.pdf. Acesso: 12 jan. 2012

INTERNATIONAL LAW COMISSION. Report of the Sixty-Seventh Conference, Helsinki. London: International Law Association. 1996. p. 402-425.

INTERNATIONAL LAW COMISSION. Report of the Seventy-First Conference, Berlin. London: International Law Association. 2004. p. 334-421.

INTERNATIONAL LAW INSTITUTE - ILI. International Regulation regarding the Use of International Water-courses for purposes other than navigation - Declaration of Madrid, 20 April 1911. Disponível online em: http://www.fao.org/docrep /005/W9549E/w9549e08.htm\#bm08.1.2 . Acesso em: 05/05/2011

INTERNATIONAL LAW INSTITUTE - ILI. Resolution on the Use of International NonMaritime Waters. Salzburg, 11 September, 1961. Disponível online em: http://www.fao.org/DOCREP/005/W9549E/w9549e08.htm. Acesso em: 05/05/2010. 
INTERNATIONAL NETWORK OF BASIN ORGANIZATIONS (INBO); GLOBAL WATER PARTNERSHIP (GWP). The handbook for integrated water resources management in transboundary basins of rivers, lakes and aquifers. 2012.Disponível online: http://www.inbo-news.org/IMG/pdf/MGIREB-UK-2012-2.pdf. Acesso em: 12 de setembro 2012.

ISLAM, N. The Law of Now-Navegational Uses of International Watercourses: Options for Regional Regime-Building in Asia. BV, Netherlands: Kluwer Law International, 2010.

ISSAR, A.; BEIN, A.; MICHAELI, A. On the ancient water of the upper Nubian sandstone aquifer in Central Sinai and southern Israel. Journal of Hydrology, v.17, n.4, p.353-374, 1972. Disponível online: http://www.sciencedirect.com/science/article/pii 10022169472900923. Acesso em: 24 fev. 2012.

JACOBI, P. R. Governança da Água no Brasil. In: RIBEIRO W. C. Governança da Água no Brasil: uma visão interdisciplinar. São Paulo: Annablume; Fapesp; CNPq, 2009. p. 35 a 60.

JARVIS, T. W. Water Wars, War of the Well, and Guerilla Well-fare. Ground Water, v.48, n. 3, p. 346-350, 2010a.

JARVIS, T. W. Peak Water Meets Peak Oil: Moving Toward Unitization of Transboundary Aquifers. IN ISARM INTERATIONAL CONFERENCE., "Transboundary aquifers: challenges and new directions" [CD-ROM]. Pre-proceedings.UNESCO, 6-8 December 2010b. Paris: UNESCO.

JARVIS, T. W.; GIORDANO, M; PURI, S.; MATSUMOTO, K.; WOLF, A. International borders, groundwater flow and hydroschizophrenia. Ground water, v. 43, n.5, p. 764-770, 2005 .

JOHANNESBURG DECLARATION ON SUSTAINABLE DEVELOPMENT. adopted at the 17th plenary meeting of the World Summit on Sustainable Development, on 4 September 2002. Disponível online: http://www.un.org/esa/sustdev/documents/WSSD POI_PD/ English/POI_PD.htm. Acesso em 23 fev. 2012.

KASPERSON, R.; RENN, O.; SLOVIC P.; BROWN, H. S.; EMEL, J.; GOBLE, R.; KASPERSON, J.X.; RATICK, S. The social amplification of risk. A conceptual framework. Risk Analysis, v. 8, n.2, p.177-187, 1988.

KLINK, F. A; MORIANA, E. P; GARCIA, J. S. The social construction of scarcity. The case of water in Tenerife (Canary Islands). Social Process of Environmental Valuation. Ecological Economics, v. 34, n. 2, p. 233-245, August 2000. 
KOLSTAD, C. D. Environmental Economics. Nova York: Oxford University Press, 2000.

KUOKKANEN, T. International Law and the Environment: variations on a theme. The Erik Castrén Institute of International Law and Human Rights. The Hague: Kluwer Law International, 2002.

LABORDE, L. C. The law of transboundary aquifers and the Berlin Rules on Water resources (ILA): Interpretative Complementarity. IN ISARM INTERATIONAL CONFERENCE., "Transboundary aquifers: challenges and new directions" [CD-ROM]. Preproceedings.UNESCO, 6-8 December 2010. Paris: UNESCO.

LALL, U.; HEIKKILA, T.; BROWN, C.; SIEGFRIED, T. Water: A Global Challenge : Water in the 21st Century: Defining the Elements of Global Crises and Potential Solutions. Journal of International Affairs, v.61, n.2, p. 1-17, 2008.

LASZLO, E. The systems view of the world: The natural philosophy of the new developments in the sciences. Nova York: George Braziller, 1972.

LABORATÓRIO DE ESTUDOS DE BACIAS/ UNIVERSIDADE ESTADUAL PAULISTA - LEBAC/UNESP. Informe final de hidrogeologia - Projeto para a Proteção Ambiental e Desenvolvimento Sustentável do Sistema Aquífero Guarani. Consórcio Guarani. Rio Claro: Departamento de Geologia Aplicada (DGA) do Instituto de Geociências e Ciências Exatas (IGCE). Universidade Estadual Paulista (UNESP), 2008.

LEITE, J. R. M.; AYALA, P. A. Direito ambiental na sociedade de risco. 2 ed. Rio de Janeiro: Forense Universitaria, 2004.

LEFF, E. Saber Ambiental: sustentabilidade, racionalidade, complexidade, poder. 3ed. Petrópolis, RJ: Vozes, 2001.

LEFF, E. Pensar a complexidade ambiental. In: LEFF, E. (Org.). A Complexidade Ambiental. São Paulo: Cortez, 2003, p.15-64.

LEFF, E. Ecología y Capital: Racionalidad Ambiental, Democracia Participativa y Desarrollo Sustentable. 7ed. Madrid: Siglo XXI Editores, 2007. 
LICHTENBERG, E.; ZILBERMAN, D.; BOGEN, K. T. Regulating environmental health risks under uncertainty: Groundwater contamination in California. Journal of Environmental Economics and Management, v. 17, n. 1, p. 22-34, July, 1989.

LIMA, G. C. O discurso da Sustentabilidade e suas implicações para a educação. Ambiente e Sociedade: v. 6, n. 2, p. 99-119, 2003.

LLAMAS, M. R; GARRIDO, A. Lessons for intensive groundwater use in Spain: Economic and Social Benefits and Conflicts. In: GIORDANO, M.; VILlhOLTH, K. G. The Agricultural Groundwater Revolution: opportunities and threats to development. Cambridge, MA: Cabi, 2007. p. 266-295.

LOBINA, E.; HALL, D. Public Sector Alternatives to Water Supply and Sewerage Privatization: Case Studies. International Journal of Water Resources Development, v.16, n. 1, p.35-55, 2000.

LOBOSCO, O. S. Modeling and simulation of DC motor in dynamic conditions. In: IEEE INTERNATIONAL ELECTRIC MACHINES AND DRNES CONFERENCE RECORD, 1997, Milwaukee. Proceedings. IEMDC 97. Piscataway: IEEE, 1997, p. MB2 1/1-3

LOS COBOS, G. La recarga artificial de acuífero como ayuda a la gestión de los recursos hídricos; el ejemplo del sistema de Ginebra (Suiza). Boletín Geológico y Minero, v. 120, n. 2, p. 305-310, 2009.

LOS COBOS, G. The transboundary aquifer of the Geneva region (Switzerland and France): successfully managed for 30 years by the State of Geneva and French border communities. In: UNESCO-IAH-UNEP. Pre-proceedings - ISARM International Conference Transboundary Aquifers: Challenges and new directions [CD ROM]. UNESCO, 6-8 December 2010 Paris. UNESCO.

LOUKA, E. International Environmental Law: Fairness, Effectiveness, and World Order. Cambridge University Press. 2006.

MACCHESNEY, B. Lake Lanoux Case (France-Spain). The American Journal of International Law, v. 53, n. 1, p. 156-171, jan., 1959.

MARIANO, K. P. Globalização, Integração e o Estado. Lua Nova, São Paulo, v. 71, p. 123$168,2007$. 
MATOS, R, P. P. As ONG(D) e a crise do Estado soberano: um estudo de ciência política e relações internacionais. Lisboa: Universidade Lusíada Editora, 2001.

MATSUMOTO, K. Transboundary groundwater and international law: Past Practices and Current Implications. Research Paper (Master of Science) - Oregon State University, Oregon, 2002.

MAY, P. H. Economia do Meio Ambiente: Teoria e Prática. 2ed. Rio de Janeiro: Elsevier, 2010 .

MCCAFFREY, S. C. The Work of the International Law Commission relating to the Environment. Ecology Law Quaterly, v.11, n.1-2, p. 189-214, 1983.

MCCAFFREY, S. C. An assessment of the work of the international law commission. Natural Resouces Journal, v. 36, p.659-671, 1996.

MCCAFFREY, S. C. International Groundwater Law: Evolution and Context. In: SALMAN, S. M. A. Groundwater: Legal and Policy Perspectives: Proceedings of a World Bank Seminar. Washington:World Bank Publications. p. 139-162. 1999

MCCAFFREY, S. The Law of International Watercourses. Oxford: Oxford University Press, 2001.

MCCAFREY, S. C. The International Law Commission Adopts Draft Articles on Transboundary Aquifers. The American Journal of International Law, v. 103, n ${ }^{\circ}$ 2, p. 272 293. 2009.

MCCAFFREY, S. C. The International Law Commission's flawed Draft Articles on the Law of Transboundary Aquifers: the way forward. Water International, v. 36, n.5, p. 566-572, 2011.

MCINTYRE, O. International Water Law: Concepts, evolution and Development. In: EARLE, A.; JÄGERSKOG, A.; ÖJENDAL, J. Transboundary Water Management: Principles and Practice.London: Earthscan, 2010a. p. 59-71.

MCINTYRE, O. Fragmentation in International Water Resources Law: Reconciling the International Law Commission's 2008 Draft Articles on Transboundary aquifers with the 1997 UN Watercourse convention.In: UNESCO; IAH; UNEP. Pre-proceedings of ISARM international conference, "Transboundary aquifers:challenges and new directions" [CDROM]. UNESCO, 6-8 December 2010. Paris: UNESCO. 2010 b. 
MEADOWS, D. H; MEADOWS, D. L; RANDERS, J; BEHRENS III, W.W. The Limits to Growth. New York: Universe Books, 1972.

MECHLEM, K. International Groundwater Law: Towards Closing the Gaps? In: ULFSTEIN, G. (ed.). Yearbook of international environmental Law, vol. 14, Oxford: Oxford University Press, 2003. p. 47-80.

MECHLEM, K. Moving Ahead in Protecting Freshwater Resources: The international Law Commission's Draft Articles on Transboudary Aquifers. Leiden Journal of International Law, v. 22, p 801-821, 2009.

MELLO, L. I. A. Brasil e Argentina em perspectiva. Rev. hist., São Paulo, n. 147, dez 2002. Disponível em: http://www.revistasusp.sibi.usp.br/scielo.php?script=sci arttext\&pid=S003483092002000200009\&lng=pt\&nrm=isso. Acesso em: 20 de agosto de 2012.

MERCOSUL. Tratado Para a Constituição de um Mercado Comum entre a República Argentina, a República Federativa do Brasil, a República do Paraguai e a República do Uruguai. 26 de março de 1991. Disponível online: http://www.sice.oas.org/trade/mrcsrp/treatyasun_p.asp. Acesso em: 24 jan. 2010.

MERLE, M. Sociologia das Relações Internacionais. Brasília: Editora da Universidade de Brasília, 1981.

MERRIEN, F. Governance and modern welfare states. International Social Science Journal, v. 50, n. 155, p. 57-67, 1998.

MEYBECK, M.; HELMER, R. 1989 The quality of rivers: from pristine state to global pollution. Paleogeog. Paleoclimat. Paleoecol. (Global Planet. Change Sect.) v. 75, p. 283-309, apud ADRIAANSE, M.; LINDGAARD-JØRGENSEN, P. Information Systems. In: HELMER, R.; HESPANHOL, I. (Eds.) Water Pollution Control. A guide to the use of water quality management principles. London: E\&FN Spon, 1997. Disponível online: http://www.who.int/water_sanitation_health/resourcesquality/wpcchap9.pdf. Acesso em: 20 fev. 2012.

MICHON JUNIOR, W. Unitização de Jazidas de Petróleo: Uma Aplicação do Modelo de Green E Porter. 2011. 33f. Dissertação (Mestrado em Economia) - Escola de pós-graduação em economia, Fundação Getulio Vargas, Rio de Janeiro, 2011. 
MINISTÉRIO DO MEIO AMBIENTE. Águas subterrâneas: um recurso a ser conhecido e protegido. Brasília: MMA, 2007.

MOLLE F.; MOLLINGA P. Water poverty indicators: conceptual problems and policy issues. Water Policy, v. 5, p. 529-544, 2003.

MOLLE, F.; MOLLINGA, P.P.; WESTER, P. Hydraulic bureaucracies and the hydraulic mission: Flows of water, flows of power. Water Alternatives, v. 2, n. 3, p. 328-349, 2009.

MOLLINGA, P. P. Water, politics and development. Framing a political sociology of water resources management. Water Alternatives, v. 1, n.1, p. 7-23, 2008.

MONTANO, J., TUJCHNEIDER, O, AUGE, $\mathrm{M}$ et al. Acuíferos regionales en América Latina: Sistema acuífero Guaraní. Santa Fe: Universidad Nacional del Litoral Santa Fe, 1998.

MORIN, E. Saberes Globais e Saberes locais: o olhar transdiciplinar. Participação Marcos Terena. Rio de Janeiro: Garamond, 2008.

MORIN, E.; participação KARA, A. B. Terra-Pátria, tradução Paulo Azevedo Neves da Silva. Porto Alegre: Sulina, 2003.

OBSERVATOIRE DU SAHARA ET DU SAHEL - OSS. The North-Western Sahara Aquifer System: Concerted management of a transboundary water basin. Synthesis Collection No. 1. Tunis: OSS, 2008.

OEHHA. OFFICE OF ENVIRONMENTAL HEALTH HAZARD ASSESSMENT. Final Technical support document on public health goal for hexavalent chromium in drinking water. 2011. Disponível em: http://oehha.ca.gov/water/phg/072911 Cr6PHG.html. Acesso em: 23 jan. 2012.

OLIVEIRA, I. T. M. A ordem internacional em transformação: uma análise em três dimensões. Boletim Meridiano, v. 13, n. 131, p. 31 a 37, mai.-jun 2012.

ORGANIZATION OF AMERICAN STATES (OAS), 2009. Guarani Aquifer: strategic action program. Acuífero Guaraní: programa estratégicode acción. Bilingual edition. Brazil: OAS. Available from: http://iwlearn.net/iw-projects/Fsp 112799467571 /reports/strategic-action-program/view . Acesso em: 7 jul. 2010. 
ORGANIZAÇÃO DAS NAÇÕES UNIDAS. Declaração do Rio sobre Meio Ambiente e Desenvolvimento. Conferência das Nações Unidas sobre Meio Ambiente e Desenvolvimento, Rio de Janeiro, 3 a 14 de junho de 1992 . Disponível online: http://www.onu.org.br/rio20/img/2012/01/rio92.pdf. Acesso: 22 de julho de 2012.

O'RIORDAN T, VOISEY H. The political economy of the sustainability transition. In: O'RIORDAN, T; VOISEY, H. (eds.). The Transition to Sustainability: The Politics of Agenda 21 in Europe. London: Earthscan, 1998. p 3 - 30.

OSTROM, E. Governing the Commons: The Evolution of Institutions for Collective Action. New York: Cambridge University Press, 1990.

NASSER, S. H. Jus Cogens: Ainda esse desconhecido. Revista Direito FGV, São Paulo, v. 1, n. 2, p. 161-178, 2005a.

NASSER, S. H. Desenvolvimento, Costume Internacional e Soft Law. In: AMARAL JÚNIOR, A. (Org.). Direito Internacional e Desenvolvimento. 1 ed. Barueri: Manole, 2005b. p. 201-218.

NASSER, S. H. Direito internacional do meio ambiente, Direito transformado, jus cogens e soft law. In: NASSER, S. H.; REI, F. (Orgs). Direito Internacional do Meio Ambiente. São Paulo: Atlas, 2006. p.19-30.

PACHOVA, N. I.; JANSKY, L. Domestic drivers of international water security on the Danube. In: PACHOVA, N. I.; NAKAYAMA, M; JANSKY, L. (Orgs.). International Water Security: domestic threats and opportunities. Tokio: United Nations University Press, 2008. p. 61-78.

PALMA, C. R. Joint Quantity/Quality Management of Groundwater. Environmental and Resource Economics, v. 26, n.1, p. 89-106, 2003.

PARLAMENTO DEL MERCOSUR. Creación del Instituto Regional e Investigaciones y Desarrollo Del Agua Subterránea. MERCOSUR/PM/SO/REC. 25/2009. 2009a.

PARLAMENTO DEL MERCOSUR. Propuesta de Proyecto de Norma que establece un Acuerdo-Marco sobre la cooperación para la conservación y uso sostenible de los recursos hídricos del Acuífero Guaraní en el MERCOSUR. MEP/216/2009. 2009b. Disponível online: http://www.parlamentodelmercosur.org/innovaportal/file/3165/1/33 2009pn.pdf. Acesso: 23 jan. 2010. 
PARLAMENTO DO MERCOSUL. Proyecto de Recomendación referente al diseño de una política común respecto al uso del acuífero guaraní. AE/VII SO/2007/nº55. 2007.

PERMANENT COURT OF INTERNATIONAL JUSTICE - PCIJ. Jurisdiction of the European Commission of the Danube between Galatz and Braila (Reino Unido, França, Itália vs. Romênia). Publications of the Permanent Court of International Justice. Collection of Judgments Series B.- $n^{\circ}$ 13. December, 8 th, 1927.

PERMANENT COURT OF INTERNATIONAL JUSTICE - PCIJ. Case relating to the territorial, jurisdiction of the International Commission of the River Oder (Alemanha, Dinamarca, França, Reino Unido, Tchecoslováquia e Suécia v. Poland). Collection of Judgments Series A.- $\mathrm{n}^{\circ}$ 23.10 September, 1929. Disponível online: http://www.icjcij.org/pcij/serie A/A 23/74_Commission_internationale de 1 Oder Arret.pdf. Acesso em: 25 jan. 2012.

PERMANENT COURT OF INTERNATIONAL JUSTICE - PCIJ. Diversion of Water from Meuse (Netherlands v. Belgium). Publications of the Permanent Court of International Justice Series A/B - no.70. 28 June 1937. Disponível online: http://www.icj-cij.org/pcij/series-ab.php?p1=9\&p2=3. Acesso em: 23 jan. 2012.

PERREZ, F. X. Relationship between Permanent Sovereignty and the Obligation Not to Cause Transboundary Environmental Damage. Environmental Law, v. 26, n 1200, p.1187$1212,1996$.

PIDGEON, N.; KASPERSON, R. E.; SLOVIC, P. The Social Amplification of Risk. Cambridge: Cambridge University Press, 2003.

PITT, R.; CLARK, S.; PARMER, K. Potential Groundwater Contamination from Intentional and Non-intentional Stormwater Infiltration; Washington, DC: U.S. Environmental Protection Agency, 1994.

POSTEL S, RICHTER B. Rivers for Life: Managing Water for People and Nature. Washington, DC: Island Press, 2003.

PURI, S. (Ed.). Internationally shared (transboundary) aquifer resources management. ISARM Americas: overview and suggested next steps for discussion at the Montevideo Meeting 24th \& 25th September 2003. Disponível em: http://www.iah.org/isarm/shammy.pdf. Acesso em: 23 ago. 2006

PURI, S.; STRUCKMEIER, W. Aquifer Resources in a Transboundary Context: A hidden resource? Enabling the practitioner to 'see it and bank it' for good use. In: EARLE, A.; JÄGERSKOG, A.; ÖJENDAL, J. Transboundary Water Management: Principles and Practice.London: Earthscan, 2010. p. 73-90. 
REBOUÇAS, A. C. Águas Subterrâneas, In: REBOUÇAS, A. C; BRAGA, B; TUNDISI, J.G. (Orgs). Águas doces no Brasil: Capital ecológico, uso e conservação. 3ed. São Paulo: Escrituras editora, 2006. p. 111-144.

RIBEIRO, R. A. Fontes do direito internacional do meio ambiente e propostas para a segurança ambiental global. 2002. 199f. Dissertação (Mestrado em Direito Internacional Público) -Faculdade de Direito, Universidade de São Paulo. São Paulo.

RIBEIRO, W. C. A ordem ambiental internacional. 2ed. São Paulo: Contexto, 2001.

RIBEIRO, W. C. O Brasil e a Rio+10. Revista do Departamento de Geografia, v. 15, p. $37-$ 44, mai.-jun. 2002.2 Disponível online: http://citrus.uspnet.usp.br/rdg/ojs/index.php/rdg/article/view/60/50. Acesso em: 12 de junho de 2012

RIBEIRO, W. C. Geografia Política e Recursos Naturais. Mercator - Revista de Geografia da UFC, v.3, n. 5, p. 73-78, 2004.

RIBEIRO, W. C. Geografia Política da água. São Paulo: AnnaBlume, 2008a.

RIBEIRO, W. C. Aqüífero Guarani: gestão compartilhada e soberania. Estudos Avançados, São Paulo, v. 22, n. 64, Dec. 2008b. Disponível online: http://www.scielo.br/scielo.php?script=sci arttext\&pid=S0103-4014200800030001 4\&lng=en\&nrm=iso. Acesso em: 10 set. 2010.

RIBEIRO, W. C. Impasses da Governança da Água no Brasil. In: Ribeiro W. C. Governança da Água no Brasil: uma visão interdisciplinar. São Paulo: Annablume; Fapesp; CNPq, 2009. p. 111 a 134 .

RIBEIRO, W. C. Geografia política e gestão internacional dos recursos naturais. Estudos avançados, v. 24, n. 68, 2010a. Disponível em <http://www.scielo.br/scielo .php?script=sci_arttext\&pid=S0103-40142010000100008\&lng=pt\&nrm=iso $>$. Acesso em: 09 maio 2012.

RIBEIRO, W. C. Teorias socioambientais: em busca de uma nova sociedade. Estudos avançados, São Paulo, v. 24, n. 68, 2010b. Disponível online: http://www.scielo.br/scielo.php?pid=S0103-40142010000100003\&script=sci_arttext. Acesso em: 23 jan. 2012. 
RIBEIRO, W. C. Soberania: Conceito e Aplicação para a Gestão da Água. In: XII Coloquio Internacional de Geocrítica. Las independências y construcción de estados nacionales: poder, territorialización y socialización, siglos XIX-XX. Bogotá: Universidad Nacional de Colombia, 7 a 11 de mayo de 2012. Disponível online:

http://www.ub.edu/geocrit/coloquio2012/actas/05-W-Costa.pdf. Acesso em: 23 set. 2012.

RIJSBERMAN, F. R. Water Scarcity: Fact or Fiction? Agricultural Water Management, v.80, n. 1-3, p. 5-22, 2006. Disponível online: http://www.sciencedirect.com/science/ article/pii/S0378377405002854. Acesso: 23 jan. 2012.

ROBERTS, A. E. Traditional and modern approaches to customary international law: a reconciliation. The Americam Journal of International Law, v. 95, n.4, p. 757-791, 2001.

RODRIGUES JUNIOR, G. S. Geografia Política e os recursos hídricos compartilhados: o caso Israelo-Palestino. 2010. $231 \mathrm{f}$. Tese (Doutorado em Geografia) - Faculdade de Filosofia, Letras e Ciências Humanas. Universidade de São Paulo, São Paulo, 2010.

ROMEIRO, A. R. Economia ou economia política da sustentabilidade. In: MAY, P. H.; LUSTOSA, M. C.; VINHA, V.; ROMEIRO, A. R. (Orgs.). Economia do Meio Ambiente Teoria e Prática. Rio de Janeiro: Editora Campus, 2003, v. 1, p. 1-29.

ROSA FILHO, E. F. Histórico sobre o Projeto "Sistema Aqüífero Guarani". Perfuradores.com. 2003. Disponível online: http://www.pocoartesianobr.com. br/index.php?CAT=pocosagua \&SPG=noticias \&TEMA=Saiba\%20Mais \&NID=0000000556.

Acesso: 12 jun. 2012.

ROSENAU, J. N. Governança, Ordem e Transformação na Política Mundial. In: ROSENAU, J. N; CZEMPIEL, E. O. Governança sem governo: ordem e transformação na política mundial. Brasília: Editora Universidade de Brasilia: 2000. p. 11. 46.

RUIZ, J. J. Derecho Internacional de Medio Ambiente. Madrid: McGraw Hill, 1999.

SACHS, I. Em busca de novas estratégias de desenvolvimento. Estudos avançados, São Paulo, v. 9, n. 25, p. 29-63, dec. 1995. Disponível online: $<$ http://www.scielo.br/scielo.php?script=sci_arttext\&pid=S0103-40141995000300004 \&lng=en\&nrm=iso $>$. Acesso em: 07 Maio 2012.

SACHS, I. Rumo a ecossocioeconomia: Teoria e Prática do Desenvolvimento. São Paulo: Cortez, 2007. 
SAHARA AND SAHEL OBSERVATORY (OSS). The North-Western Sahara Aquifer System (Algeria, Tunisia, Libia) Concerted management of a transboundary water basin. Synthesis Report $\mathrm{n}^{\circ}$ 1. OSS: Tunis, 2008

SALIH, A. Qanats a unique groundwater management tool in arid regions: The case of Bam region in Iran. International Symposium on Groundwater Sustainability, 2006. p. 79-87.

SALMAN, M. A. S The present state of research carried out by the English speaking section of the centre for studies and research. In: Hague Academy of International Law. Water Resources and International Law. Hague: Kluwer Law International. 2002, p. 63-120.

SALMAN, S. M. A. The Helsinki Rules, the UN Watercourses convention and the Berlin Rules: Perspectives on International Water Law. Water Resources Development, v. 23, n. 4, p.625-640, 2007a.

SALMAN, S. M. A. The United Nations Watercourses Convention Ten Years Later: Why Has its Entry into Force Proven Difficult? Water International, v. 32, n. 1, p. 1-15, $2007 \mathrm{~b}$.

SALMAN S.; MCINERNEY-LANKFORD, S. The Human Right to Water - Legal and Policy Dimensions. Washington, DC: Law, Justice, and Development Series, The World Bank. 2004. Disponível online em: http://www.ila-hq.org/en/committees/index.cfm/cid/32.

SAMPAT, P. Deep trouble: the Hidden Threat of groundwater pollution. Washington: Worldwatch Institute, 2000.

SANDS, P. Principles of International Environmental Law. 2ed. Cambridge: University Press, 2003

SANTOS, B. S. Porque é tão difícil construir uma teoria crítica? Revista Crítica de Ciências Sociais, ${ }^{\circ}$ 54, p. 197-215, jun, 1999.

SANTOS, M. Espaço e Método. São Paulo: Nobel, 1985.

SANTOS, M. Técnica, espaço, tempo, globalização e meio técnico -cientifico informacional. São Paulo: Editora Hucitec, 1994.

SANTOS, M. A natureza do espaço: técnica e tempo, razão e emoção. São Paulo: Editora da Universidade de São Paulo, 2002. 
SATO, E. A agenda internacional depois da Guerra Fria: novos temas e novas percepções. Política Internacional, v. 43, n.1, p. 138-169, 2000.

SCHRIJVER, N. Sovereignty over natural resources: balancing rights and duties. New York: Cambridge University Press, 1997.

SCHREUER, C. The Warning of the Sovereign State: Towards a New Paradigm for International Law. European Journal of International Law, v. 4, n.1, p. 447-471, 1993.

SECOND WORLD WATER FORUM Ministerial Declaration of the Hague on Water Security in the 21 st Century. The Hague, The Netherlands, 22 de março de 2000. Disponível online: http://www.idhc.org/esp/documents/Agua/Second_World_Water_Forum[1].pdf. Acesso: 3 jan. 2012.

SECRETARIA GENERAL. Informe Semestral de Actividades de la Secretaría General. Período Diciembre de 2004 Junio de 2005. Proyecto para la Protección Ambiental y Desarrollo Sostenible del Sistema Acuífero Guarani. 2005. Disponível online: http://projects.csg.uwaterloo.ca/inweh/display.php?ID=1835. Acesso em: 3 set. 2012.

SECRETARIA GENERAL. Informe Semestral de Actividades Secretaría General. Período Julio de 2005 Diciembre de 2005,Ampliado a Marzo de 2006. Proyecto para la Protección Ambiental y Desarrollo Sostenible del Sistema Acuífero Guarani. 2006a. Disponível online: http://projects.csg.uwaterloo.ca/inweh/display.php?ID=1834. Acesso em: 3 set. 2012.

SECRETARIA GENERAL. Informe Semestral de Actividades Secretaría General Período Abril de 2006 Setiembre de 2006 (actividades ajustadas hasta Octubre). Proyecto para la Protección Ambiental y Desarrollo Sostenible del Sistema Acuífero Guarani. 2006b. Disponível online: http://projects.csg.uwaterloo.ca/inweh/display.php?ID=1833. Acesso em: 3 set. 2012 .

SECRETARIA GENERAL. Informe Julio 2008. Proyecto para la Protección Ambiental y Desarrollo Sostenible del Sistema Acuífero Guarani. 2008. Disponível online: http://projects.csg. uwaterloo.ca/inweh/display.php?ID=1895. Acesso em: 3 set. 2012.

SEVERINO, A. J. Metodologia do trabalho científico. 23. ed. rev. e atual. São Paulo: Cortez, 2007. 
SHAH, T., BURKE, J.J, VILLHOLTH, K. Groundwater: a global assessment of scale and significance. In: MOLDEN, D. Water for Food, Water for Life. London: Earthscan, 2007, p. $395-423$.

SHENG, Z.; DEVERE, J. Understanding and managing the stressed Mexico-USA transboundary Hueco bolson aquifer in the El Paso del Norte region as a complex system. Hydrogeology Journal, v. 13; n. 5-6, p. 813-825, 2005.

SHIKLOMANOV, I. A.; RODDA, J.C. (Eds.). World water resources at the beginning of the 21st century. Cambridge, UK: UNESCO International Hydrology Series, 2003.

SHIVA, V. Water wars: privatization, pollution and profit. Cambridge, MA: South End Press, 2002.

SIEBERT, S.; BURKE, J.; FAURES, J. M.; FRENKEN, K.; HOOGEVEEN, J.; DÖLL, P.; PORTMANN, F.T. Groundwater use for irrigation — a global inventory. Hydrology \& Earth Systems Science, v.14, p. 1863-1880, 2010.

SIMMA, B. The Contribution of Alfred Verdross to the Theory of International Law. European Journal International Law, v. 1, p. 19-22, 1995.

SIMMA, B.; ALSTON, P. The Sources of Human Rights Law: Custom, Jus Cogens, and General Principles. Australian Year Book of International Law. 1988-1989.

SINDICO, F., 2010. The management of the GAS: what role for the emerging international law of transboundary aquifers? In: UNESCO; IAH; UNEP. Pre-proceedings of ISARM international conference, "Transboundary aquifers:challenges and new directions" [CDROM]. UNESCO, 6-8 December 2010. Paris: UNESCO. 2010.

SMITH A. H.; LINGAS E. O; RAHMAN M. Contamination of drinking-water by arsenic in Bangladesh: a public health emergency. Bulletin World Health Organization, v. 78, n. 9, p.1093-1103, 2000. Disponível online: http://www.ncbi.nlm. nih.gov/pubmed/11019458. Acesso em: 4 fev. 2012.

SMOUTS, M. C. The proper use of governance in international relations. International Social Science Journal, v. 50, n. 155, p. 81-89, 1998.

SOARES, G. F. S. Direitos Humanos e Meio Ambiente. In: AMARAL JUNIOR, A.; PERRONE-MOISÉS, C. (Orgs.). O cinqüentenário da Declaração Universal dos Direitos do Homem. São Paulo: EDUSP, 1999. p. 121- 177. 
SOARES, G. F. S. Direito Internacional do Meio Ambiente: emergência, obrigações e responsabilidades. São Paulo: Atlas, 2001.

SOARES, G. F. S. A proteção internacional do meio ambiente. Barueri-SP: Manole, 2003.

SPRING, U. O.; BRAUCH, H. G. Securitizing Water. In: BRAUCH, H. G. et al. Facing Global Environmental Change: Environmental, Human, Energy, Food, Health and Water Security Concepts. Heidelberg: Springer, 2009. p. 175-202.

STEPHAN, M. R. Transboundary aquifers: managing a vital resource. The UNILC draft articles on the law of transbounday aquifers. Paris: Unesco, 2009.

STOKER, G. Public Private Partnerships and Urban Governance. In: PIERRE, J (ed). Partnerships in Urban Governance: European and American Experience. London: Macmillan Press. 1997. p. 34-51.

THEESFELD, I. Institutional aspects of groundwater governance. In: SCHEUMANN, W.; HERRFAHRDT-PÄHLE, E. Conceptualizing cooperation on Africa's transboundary groundwater resources. Bonn: German Development Institute, 2008, p. 305-338.

THE FEDERAL GOVERNMENT OF GERMANY. Ministerial Declaration, The Bonn Keys and Bonn Recommendations for Action. International Conference of Freshwater. December, 2001 . p. 3-7. Disponível online: http://www.umweltdaten.de/wasser-e/w-ksd.pdf. Acesso em: 2 jan. 2012.

THENKABAIL, P.S., BIRADAR C.M., NOOJIPADY, P., DHEERAVATH, V., LI, Y.J., VELPURI, M., GUMMA, M., REDDY, G.P.O., TURRAL, H., CAI, X. L., VITHANAGE, J., SCHULL, M.; DUTTA, R. Global irrigated area map (GIAM), derived from remote sensing, for the end of the last millennium. International Journal of Remote Sensing, v. 30, n. 14, p. 3679-3733, 2009.

THIERRY, H. L'evolution du droit international: cours géneral de droit international public. RCADI, 1999, t. 222, p. 9-186, apud ACCIOLY, H; SILVA, G. E. N.; CASELLA, P. B. Manual de Direito Interna cional Público. 17 ed. São Paulo: Saraiva, 2009.

UHLMANN, E. M. K. State Community Interests, Jus Cogens and Protection of the Global Environment: Developing Criteria for Peremptory Norms. Georgetown International Law Review, 101. 1998. 
UNITED NATIONS. Declaration of the United Nations Conference on the Human Environment. United Nations Conference on the Human Environment, Stockholm, 5- 16 June, 1972. Disponível online: http://untreaty.un.org/cod/avl/ha/dunche/dunche.html. Acesso: 22 de maio de 2012

UNITED NATIONS. Report of the United Nation Water Conference, Mar del Plata, March 14-25, 1977, U.N Sales $n^{\circ}$ E77. II A. 12, 1977, apud. CAMPONERA, D. A. National and International Water Law and Administration: Selected Writings. The Hague: Kluwer Law International, 2003.

UNITED NATIONS. Report of the World Commission on Environment and Development Our Common Future. 1987. Disponível online: http://conspect.nl/pdf/Our_Common_Future-Brundtland_Report_1987. pdf. Acesso em: 23 de agosto de 2012 .

UNITED NATIONS DEVELOPMENT PROGRAM - UNDP. Beyond Scarcity: Power, Poverty and the Global Water Crisis. Human Development Report. United Nations Development Programme. New York, USA. 2006.

UNITED NATIONS ECONOMIC COMMISSION FOR EUROPE - UN/ ECE TASK FORCE ON MONITORING \& ASSESSMENT. Guidelines on Monitoring and Assessment of Transboundary Groundwaters. Lelystad, March 2000. Disponível online: http://www.unece.org/fileadmin/DAM/env/water/publications/documents/ guidelinesgroundwater.pdf. Acesso: 23 nov. 2011.

UNITED NATIONS EDUCATIONAL SCIENTIFIC AND CULTURAL ORGANIZATION 0 UNESCO. Final Report International Hydrological Decade. Paris, 27 February 1973. Disponível online: http://unesdoc.unesco.org/images/0000/000042/004265EB.pdf. Acesso em: 23 jul. 2012.

UNESCO-IHP. Methodology for the GEF Transboundary Waters Assessment Programme. vol. 2. Methodology for the Assessment of Transboundary Aquifers, UNEP, 2011. Disponível online: http://www.unep.org/dewa/Portals/ 67/pdf/TWAP-Volume-2Methodology for_Aquifers-low-res.pdf. Acesso: 4 jan. 2012.

UNESCO IHP ISARM PROGRAM. Atlas of Transboundary Aquifers: Global maps, regional cooperation and local. Inventories International Hydrological Programme. Paris: UNESCO/ISARM, 2009.

UNESCO/OEA/ISARM AMERICAS. Sistemas Acuíferos Transfronterizos en las Américas. Evaluación Preliminar. Montevideo/Washington: UNESCO, 2007. Disponível 
online em: http://www.oas.org/dsd/WaterResources/projects/ISARM/Publications/ISARM AmericasLibro 1\%28spa\%29.pdf. Acesso: 23 jan. 2012;

UNITED NATIONS ENVIRONMENTAL PROGRAM - UNEP. Vital Water Graphics 2. An Overview of the State of the World's Fresh and Marine Waters - 2nd Edition - 2008 United Nations Environment Programme. Disponível online: http://www.grida.no/publications/vg/water2/. Acesso em: 23 jul. 2012.

UNITED NATIONS GENERAL ASSEMBLY - UNGA. Resolution. 523 (VI) -Integrated economic development and commercial agreements. 12 January 1952a. Disponível online: http://www.un.org/documents/ga/res/6/ares6.htm. Acesso: 23 jun 2011.

UNGA. Resolution 626 (VII) - Right to exploit freely natural wealth and resources. 21 December 1952b. Disponível online: http://www.un.org/documents/ga/res/7/ares7.htm. Acesso: 23 jun 2011.

UNGA. Resolution 1314 (XIII) - Recommendations concerning international respect for the rights of peoples and nations to self-determination. 12 December 1958. Disponível online: http://www.un.org/documents/ga/res/13/ares13.htm. Acesso: 23 jun 2011.

UNGA. Resolution 1515 (XV) - Concerted action for economic development of economically less developed countries. 15 December 1960. Disponível online: http://www.un.org/depts/dhl/resguide/r15.htm. Acesso: 23 jun 2011.

UNGA. Resolution 1803 (XVII). Permanent sovereignty over natural resources. 14 December 1962. Disponível online: http://www2.ohchr.org/english/law/resources.htm. Acesso: 23 jun 2011.

UNGA. Resolution 2398 (XXIII). Problems of the human environment., 3 December 1968. Disponível online: http://daccess-dds-ny.un.org/doc/RESOLUTION/GEN/NR0/243/58/IMG /NR024358.pdf?OpenElement. Acesso: 23 jan. 2012.

UNGA. Resolution 3129 (XXVIII) - Cooperation in the field of the Environment concerning Natural Resources Shared by Two or More States. 13 December 1973. Disponível online: http://www.un.org/documents/ga/res/28/ares28.htm. Acesso: 23 jun 2011.

UNGA. Resolution 3281 (XXIX) - Charter of Economic Rights and Duties of States. 12 December 1974. Disponível online: http://www.un-documents.net/a29r3281.htm. Acesso: 23 jun 2011. 
UNGA. Resolution 3513 (XXX). United Nations Water Conference. 15 December 1975. Disponível online: http://daccess-dds-ny.un.org/doc/RESOLUTION/GEN/NR0/002/26/IMG /NR000226.pdf?OpenElement. Acesso: 23 jan. 2012.

UNGA. Resolution 43/196. 83rd plenary meeting, 20 December 1988. United Nations conference on environment and development. Disponível online: http://www.un.org/documents/ga/res/43/a43r196.htm. Acesso: 23 jan. 2012

UNGA. Resolution 44/228. United Nations Conference on Environment and Development. 85th plenary meeting, 22 December 1989. Disponível online: http://www.un.org/documents/ga/res/44/ares44-228.htm. Acesso: 23 jan. 2012

UNGA. Resolution 45/181. International Drinking Water Supply and Sanitation Decade. 71st plenary meeting. 21 December 1990. Disponível online: http://www.un.org/documents/ga/res/45/a45r181.htm. Acesso: 23 fev. 2012.

UNGA. Resolution 55/2 - United Nations Millennium Declaration. 8th plenary meeting. 8 September 2000. Disponível online: http://www.un.org/millennium/declaration/ares55 2e.htm/. Acesso 4 jul. 2012.

UNGA. Resolution 63/124. The law of transboundary aquifers. 67th plenary meeting. 11 December 2008. Disponível online: http://daccess-dds-ny.un.org/doc/UNDOC/GEN/N08/478 /23/PDF/N0847823.pdf?OpenElement. Acesso: 3 jan. 2010.

UNGA. Resolution 64/236. Implementation of Agenda 21, the Programme for the Further Implementation of Agenda 21 and the outcomes of the World Summit on Sustainable Development. General Assembly, Sixty-fourth session, 31 March 2010. Disponível online: http://www.un.org/en/ga/president/65/issues/sustdev.shtml. Acesso: 4 fev. 2012.

UNGA. Draft resolution, submitted by the President of the General Assembly The future we want. 24 July 2012. Disponível online: http://daccess-ddsny.un.org/doc/UNDOC/LTD/N12/436/88/PDF/N1243688.pdf?OpenElement. Acesso 6 de julho de 2012.

UNITED NATIONS SYSTEM. Administrative Committee on Coordination. InterAgency Committee on Sustainable Development Report of the ACC Subcommittee on Water Resources on its twenty-second session . WMO Headquarters, Geneva, 24-28 September 2001. Disponível online: http://www.un.org/esa/sustdev/sdissues/ water/acc22_report.pdf. Acesso: 2 jul. 2012. 
UNITED NATIONS WATER. Copping with water scarcity: challenge of the twenty first century. World Water day. UN WATER, 2007. Disponível online: http://www.unwater.org/downloads/ escarcity.pdf. Acesso: 22 junho 2012.

UNITED NATIONS WATER. Transboundary Waters: Sharing Benefits, Sharing Responsibilities. Thematic Paper. UN Water, 2008.

UN WATER; WWAP. Water: A shared responsibility. The United Nations World Development Report 2. Barcelona: UNESCO, 2006. Disponível online em http://www.unesco.org/water/wwap/wwdr/wwdr2/pdf/wwdr2_ch_2.pdf. Acesso em 23 jan. 2010. Acesso em: 4 ago. 2010.

UNITED NATIONS; WORLD WATER ASSESSMENT PROGRAMME - UN-WWAP. Water for people, water for life. Paris: UNESCO, 2003. Disponível em: $<$ http://www.unesco.org/publishing $>$. Acesso em: 23 dez. 2005.

UNITED STATES OF AMERICA. ENVIRONMENTAL PROTECTION AGENCY - EPA. Chromium-6 in Drinking Water. Office of Water. Washington: EPA, 2010. Disponível online: http://water.epa.gov/drink/contaminants/basicinformation/upload/chromium6indri nkingwater.pdf. Acesso: 23 jan. 2012

UNITED STATES OF AMERICA. ENVIRONMENTAL PROTECTION AGENCY - EPA. Drinking Water Contaminants: List of Contaminants and Their Maximum Contaminant Level (MCLs). Washington: EPA, 2009. Disponível online: http://water.epa.gov/drink/ contaminants/index.cfm\#List. Acesso: 03 fev. 2012

VAILLANCOURT, J. G. Sustainable Development: A sociologist's view of the definition, origins and implications of the concept. In: MEHTA, M. D.; OUELLET, E. Environmental Sociology: theory and practice. North York, Ontario: Captus Press, 1995. p. 219-230.

VASCONCELlos, M. J. E. Pensamento sistêmico: O novo paradigma da ciência. Campinas: Papirus, 2002.

VEYRET, Y. Os riscos: o homem como agressor e vitima do meio ambiente. São Paulo: Contexto, 2007.

VILLAR, P. C. A gestão internacional dos recursos hídricos subterrâneos transfronteiriços e o Aquífero Guarani. Revista de Gestão de Águas da América Latina, v. 4, n.1, p. 63-74, 2007. 
VILLAR, P. C. Gestão das áreas de recarga do Aqüífero Guarani: o caso do município de Ribeirão Preto, São Paulo. 2008. 180f. Dissertação (Mestrado em Ciência Ambiental) Programa de Pós-Graduação em Ciência Ambiental, Universidade de São Paulo.

VILLAR, P.C. Moving toward Guarani Aquifer management: the Brazilian case. In: UNESCO; IAH; UNEP. Pre-proceedings of ISARM international conference, "Transboundary aquifers:challenges and new directions" [CD-ROM]. UNESCO, 6-8 December 2010. Paris: UNESCO. 2010.

VILLAR, P. C.; RIBEIRO, W. C. Sociedade e gestão do risco: o aquífero Guarani em Ribeirão Preto-SP, Brasil. Revista geografia Norte Grande, v. 43, p. 51-64, 2009. Disponível online: $\quad$ http://www.scielo.cl/scielo.php?script=sci arttext\&pid=S071834022009000200003\&lng=es\&nrm=iso. Acesso: 4 mar. 2012.

VILLAR, P. C; RIBEIRO, W. C. The Agreement on the Guarani Aquifer: a new paradigm for transboundary groundwater management? Water International, v.36, n. 5, p. 646-660, 2011.

VILLAR, P. C; RIBEIRO, W. C. A percepção do Direito Humano à água na ordem internacional. Revista Direitos Fundamentais \& Democracia, v. 11, n.11, p. 358-380, 2012.

WATER PARTNERSHIP PROGRAM. A Partnership for Improved Water Resources Management and Water Service Delivery. 2010. Disponível online: http://water.worldbank.org/sites/water.worldbank.org /files/WPP-Brochure.pdf. Acesso: 15 jul. 2012.

WEISS, E. B. Fairness to Future Generations: International Law, Common Patrimony, and Intergenerational Equity. Tokio: The United Nations University, 1989.

WOLF, A. T. Conflict and cooperation along international waterways, Water Policy, v. 1, n. 2, p 51-65, 1998.

WOLF, A. T. Shared waters: conflict and cooperation. Annual Review of Environmental Resources, v. 32, p. 241-269, 2007.

WOLF, A. T.; KRAMER, A.; CARIUS, A.; DABELKO, G. D. Managing Water Conflict and Cooperation. Chapter 5. In: The WorldWatch Institute. State of the World: redefining global security. Washington, D.C.: The WorldWatch Institute. 2005, p. 80-208. Disponível online: http://tbw.geo.orst.edu/publications/abst_docs/wolf_sow_2005.pdf. Acesso em: 5 de jul. 2010. 
WORLD BANK. Project for the Environmental Protection and Sustainable Development of the Guarani Aquifer System. Office Memorandum, GEF Project Brief, Latin America and the Caribbean, LCSES. 2001. Disponível em: http://www.gefweb.org /Documents/Council_Documents/GEF_C18/Regional_Guarani_Aquifer.pdf. Acesso em: 07 mar. 2006.

WORLD BANK. Latin America and Caribbean Region - Environmental Protection and Sustainable Development of the Guarani Aquifer System Project. Washington, D.C: The World Bank, 2009. Disponível online: http://documents.worldbank.org/ curated/en/2009/07/10952015/latin-america-caribbean-region-environmental-protectionsustainable-development-guarani-aquifer-system-project. Acesso em: 23 fev. 2012.

WORLD BANK; GWMATE. Groundwater Resource Management an introduction to its scope and practice. Sustainable Groundwater Management Concepts and Tools. Briefing Note series - Note 1. The World Bank. 2006. Disponível online: http://siteresources.worldbank.org/EXTWAT/Resources/4602122-1210186362590/GWM Briefing_1.pdf. Acesso: 22 nov. 2010.

WORLD BANK/ GW MATE. A iniciativa do programa sistema Aquífero Guarani: rumo a Gestão prática da água subterrânea em um contexto transfronteiriço. Washington, D.C: The World Bank; GW MATE; Water Partnership Program. 2009. Case number 9. 2009. Disponível online: $\quad$ http://siteresources.worldbank.org/INTWAT/Resources/GWMATE English_CP 09.pdf. Acesso em: 4 aug. 2010.

WORLD HEALTH ORGANIZATION - WHO. Protecting Groundwater for Health. Managing the quality of drinking water sources. London: IWA Publishing, 2006

WORLD HEALTH ORGANIZATION - WHO; UNITED NATIONS CHILDREN'S FUND UNICEF. Progress on Drinking Water and Sanitation: Special Focus on Sanitation. Joint Monitoring Programme for Water Supply and Sanitation (JMP). New York: UNICEF. Geneva: WHO, 2008.

WHO. Guidelines for drinking-water quality. 4ed. Geneva: World Health Organization Press, 2011. Disponível online: http://whqlibdoc.who.int/publications/ 2011/9789241548151_eng.pdf. Acesso em: 13 mar. 2012.

WORLD METEOROLOGICAL ORGANIZATION - WMO. The Dublin Statement on Water and Sustainable Development. International Conference on Water and the Environment, Dublin, Ireland. 1992. Disponível online: http://www.wmo.int/pages/ prog/hwrp/documents/english/icwedece.html. Acesso em: 20 jan. 2012. 
WORLD RESOURCES INSTITUTE. World Resources 2002-2004: Decisions for the Earth: Balance, Voice, and Power. Washington: World Resources Institute, 2003. Capítulo 7. Disponível online: http://www.wri.org /publication/world-resources-2002-2004-decisionsearth-balance-voice-and-power. Acesso 23 de maio de 2012.

WORLD WATER COUNCIL. World Water Vision. London: Earthscan Publications Ltd, 2000.

WORLD WATER COUNCIL. List of members july 2012. Disponível online em: http://www.worldwatercouncil.org/fileadmin/wwc/Membership/WWC_List-of-Members July-2012.pdf. Acesso em: 4 fev. 2012.

YAHN FILHO, A. Conflito e cooperação na bacia do Prata em relação aos cursos d'água internacionais (de 1966 a 1992). 2005. 147f. Dissertação (Mestrado em Relações Internacionais) - Programa de Pós-Graduação San Tiago Dantas, UNESP - UNICAMP $\mathrm{PUC} / \mathrm{SP}$.

YAMADA, C. Codification of the Law of Transboundary Aquifers (Groundwaters) by the United Nations. Water International, v. 36, n.5, p. 557-565, 2011.

YOFFE, S.; WOLF, A. T.; GIORDANO, M. Conflict and Cooperation over International Freshwater Resources: Indicators of Basins at Risk. Journal of the American Water Resources Association, v.39, n. 5, p. 1109-1126, 2003.

ZANIRATO, S. H.; RAMIRES, J. Z. C.; AMICCIE, A. G. N.; RIBEIRO, Z. M.; RIBEIRO, W. C. Sentidos do risco: interpretações teóricas. Scripta Nova: Revista de Geografia e Ciencias Sociales, v. 13, n. 785, p. 1-10, 2008.

ZAWAHRI, N. A; MITCHELL, S. M. Fragmented Governance of International Rivers: Negotiating Bilateral versus Multilateral Treaties. Paper prepared for presentation at the 2009 annual meeting of the International Studies Association, February 15-18, New York, NY.

ZEKTSER, I. S.; EVERETT, L. Groundwater Resources of the world and their use. IHPVI, Series on Groundwater no. 6. UNESCO, 2004.

ZEITOUN, M.; MIRUMACHI, N. Transboundary water interaction: reconsidering conflict and cooperation. International Environmental Agreements: Politics, Law and Economics, v.8, n. 4, p. 297-316, 2008. 